\title{
Experimental Investigation of the Pebble Bed Structure by using Gamma Ray Tomography
}

\author{
Fadha Ahmed $^{1,2}$ and Muthanna Al-Dahhan ${ }^{1,2, *}$
}

\begin{abstract}
High-energy gamma-ray computed tomography (CT scanner system) has been used to study, for the first time, the structure of the pebble bed in terms of cross-sectional time-averaged void and solids distributions, and their radial profiles along the bed height. The pebble beds were packed with pebbles of glass spheres of diameter of $d_{1}=0.0127 \mathrm{~m}, \mathrm{~d}_{2}=0.0254 \mathrm{~m}$ and $\mathrm{d}_{3}=0.05 \mathrm{~m}$ in a Plexiglas cylinder with diameter of $\mathrm{D}=0.3048 \mathrm{~m}$, with $\mathrm{D} / \mathrm{d}_{1}=24, \mathrm{D} / \mathrm{d}_{2}=12$ and $\mathrm{D} / \mathrm{d}_{3}=6$, respectively. The average void fraction of these beds were $\bar{\varepsilon}_{1}=0.389, \bar{\varepsilon}_{2}=0.40$ and $\bar{\varepsilon}_{3}=0.43$, respectively. It was found that the void and solids distribution depends on pebble size, the bed diameter and the packing method. The void radial profiles vary with the bed height for larger pebbles at the measured axial levels (0.0762, 0.1524, and $0.2286 \mathrm{~m}$ from the bed base). However, adding additional bed height on the top of the original one did not show any influence on the average voids and their radial profiles at the same measured axial levels. The experimental results indicated that void variations are normally distributed in the bulk region of the packed bed.
\end{abstract}

Keywords: Gamma Tomography, Image reconstruction, packed bed, void and solids distribution

\section{Introduction}

Pebble bed reactor (PBR) which is a graphite-moderated and helium-cooled reactor is among the very high temperature nuclear reactors (VHTRs) that has been considered as one of the six advanced concepts of the forth (IV) generation nuclear reactors besides the prismatic block reactor. These new generation nuclear plants (NGNPs) can provide improving nuclear safety (inherently safe), improving proliferation resistant, environmentally benign by minimizing wastes and nuclear resource utilization, reducing coast for constructing and operating and 
enhancing efficiency and energy conversion that allowing these to be utilized for producing process heat, needed energy for hydrogen production and electricity [1], [2], [3], [4].

In pebble bed reactors (PBRs) the nuclear fuel is contained in pebbles of graphite rather than in metallic rods that are used in light water reactors like the Boiling Water Reactor (BWR) and Pressurized Water Reactor (PWR). The graphite pebbles of typically $60 \mathrm{~mm}$ in diameters contain about 5000 to 20,000 of four layer coated TRISO nuclear fuel particles. These TRISO particles contain a fuel kernel of $\mathrm{UO}_{2}$ or other fissile fuels [5]. These fuel pebbles are very slowly cycled through the nuclear core in a dense granular down flow in the annular region of the bed where the central region of the bed is for flowing down graphite pebbles of the same size. The pebble bed is cooled by concurrently down flow of helium which enters at about $500{ }^{\circ} \mathrm{C}$ and leaves the bed at $\sim 900{ }^{\circ} \mathrm{C}$ or higher. Hence, the pebble bed reactor can be considered as a packed bed compared to the flowing gas with respect to the related residence time distributions [6].

The pebbles in PBRs are inserted randomly in the reactor core to form packed pebblebed. The pebble bed reactor continuously recirculates the fuel spheres using an on-line refueling system as illustrated in Figure 1. A slow continuous down flow of pebbles goes through the reactor core while the reactor is operating. Pebbles are continuously added at the top of the core and removed at the bottom. The pebbles pass through the reactor core several times before being fully spent. Extracted pebbles are sent through a burnup-determining radiation detector that either sends the pebble to discharge and to be replaced with a new ones or recycles it back to the core for additional burnup. This enables the PBRs to operate with very low excess nuclear reactivity and relatively low enrichments. Graphite pebble is flowing in the core of the bed as moderation while fuel pebbles flow in the surrounding region as mentioned above. 


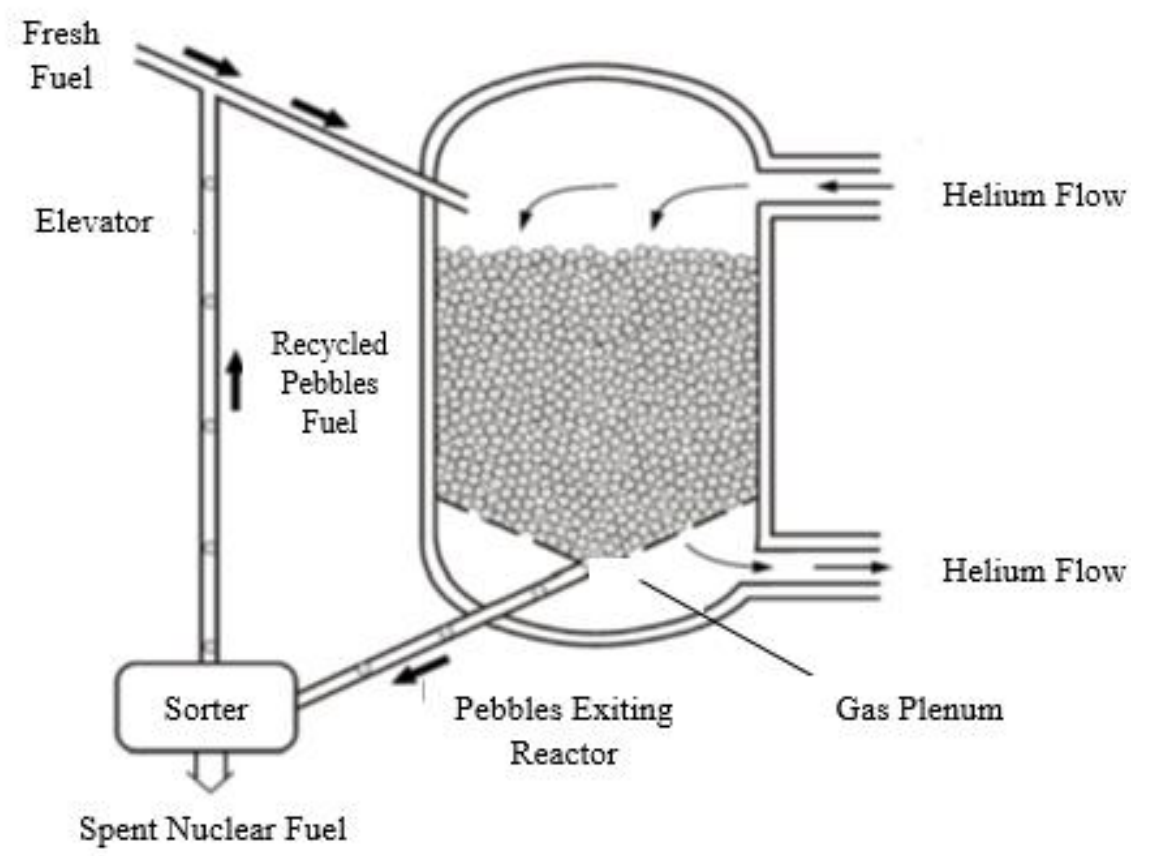

Figure 1: Online refueling schematic in a gas cooled PBR, taken from [5]

Knowledge of the packing's characteristics and the fuel pebble's behavior is important to accurately resolving core neutronics, burnup, and thermal-hydraulics. The mechanisms of fluid (helium gas) flow and heat transfer in such bed are influenced by the cross-sectional, axial and radial void volume fraction distributions (porosity) [7] and hence, it may lead to a non-uniform temperature distribution at the reactor wall and the outlet of the pebble bed due to the sharp varies of porosity from the wall to the bed center. The knowledge of the packing structure and flow patterns of pebbles in the pebble bed is thus important to any study of the transport phenomena in the reactor core as well as safety assessment [8]. Among in-core fuel cycle studies that require the knowledge of the packing distribution are the macroscopic transport and diffusion data, fuel depletion prediction, and pebble bed densification [9]. Unfortunately, the dynamic of the pebble flow is poorly understood and the bed structure has not been studied. However, it has been reported in the literature that the porosity in packed beds vary periodically from the wall. This has a major impact on the reactor physics. In addition, proper input of the bed structure (void and solids distribution) to computational fluid dynamics (CFD) including Discrete Elements Method (DEM) codes is the key for proper prediction of the CFD and DEM as 
the fluid flow in packed beds follow the least resistance path represented by high void volume fraction. However, the structure of the pebble bed, or in general, beds with large particles has not been studied experimentally in details. The minimum bulk porosity (void) of a uniform size spheres packing is about 0.36 and the typical rang of void values reported in the literature fall between 0.36 and 0.42 [10]. These literatures reported a significant variation in the void fraction in radial direction. They found that the porosity at the wall was about 1.0 (without counting the solids contact points) and that it decreased to a minimum value of about 0.25 at a distance of approximately 0.5 sphere diameters from the wall. The porosity (void) then oscillated through maximum and minimum before settling out to the bulk porosity (void) at a value of approximately 0.39 [10]. Spheres near a container wall form more ordered structures than spheres in the internal region of random packing due to a significant friction between the particles in contacting with the container wall, which leads to alignment on a cylindrical surface. The second layer of spheres will tend to lodge themselves in the deepest pockets formed by the wall spheres creating a less organized structure. The wall effect will disappear a few sphere diameters into the packing. The void fraction fluctuations from the wall inwards depends on the aspect ratio (bed diameter to particle diameter, D/d), method of charging (loading pattern) and the shape of particles [10].

Over the years several experiments have been performed to measure void fractions in cylindrical packed beds of small mono size spheres using destructive and non-destructive techniques. Early experiments of Roblee et al. [11] and Benenati and Brosilow [12], liquid wax and epoxy resin were used to fill the interstices of spheres packed bed ( $D$ is 1.62 inch, $d_{p}$ are $0.622,0.29,0.115,0.08$ inch and $\mathrm{D} / \mathrm{d}_{\mathrm{p}}$ are 2.61, 5.6, 14.1, 20.3). Upon curing of the wax or resin, the solid cylinder was machined in stages to successively smaller diameters and the weight and diameter of the cylinder was measured after each machining. In this manner the mean density of each annular ring removed could be measured and the void fraction could be determined. These experiments showed that the radial porosity presents large fluctuation near the cylinder wall that dampens out at about three to five sphere diameters from the wall towards the packed bed center. Goodling et al. [13] used a plastic cylindrical packed bed filled with small polystyrene spheres (D/d are 7.78, 7.4, 8.41, 8.56, 10.7, and 16.8). The void then filled with a mixture of epoxy and finely ground iron particles. Annular rings were then cut from the outer periphery and the bed was weighted and the void was measured. They found that the porosity is approached unity at the 
wall and then oscillated in a damped fashion toward the bed center. Kufner and Hofman [14] used a resin to fill the void between the small particles in a fixed bed (D are 20 and $42 \mathrm{~mm}, \mathrm{~d}$ are 3.5 and $4.5 \mathrm{~mm}$ with $\mathrm{D} / \mathrm{d}$ ratio of $4-12$ ). The tube was cut into layers and the cuts were polished. Photographs were taken of these cuts and analyzed with image analyzer. From these data, an average radial porosity distribution could be measured. Mueller [15] measured the center position coordinates of specially prepared Plexiglas spheres with small steel spheres at their centers in randomly packed fixed bed using X-ray radiography (D are 25.75, 50.5, 76.00 and $101.88 \mathrm{~mm}, \mathrm{~d}$ is $12.75 \mathrm{~mm}$ and $\mathrm{D} / \mathrm{d}$ are 2.02, 3.96, 5.96 and 7.99). The radial void fraction distribution was then determined from these center coordinates. Niu et al. [16] used the X-ray computed tomography to analyze the radial porosity distribution in a bed of randomly packed uniform spheres $\left(\mathrm{Dc}=0.05,0.07,0.1 \mathrm{~m}\right.$ and $\mathrm{d}_{\mathrm{p}}=1 \mathrm{~cm}$ ). Sederman et al. [17] used a magnetic resonance imaging technique (MRI) to study the porosity distribution in the radial direction in cylindrical packed beds of small balloting spheres filled with water (D is $27 \mathrm{~mm}, \mathrm{~d}_{\mathrm{p}}$ are $3,1.9$, $1.4 \mathrm{~mm}$ and $\mathrm{D} / \mathrm{d}$ are $9,14,19)$. The results from these experimental works observed oscillations in the porosity distribution in the radial direction which were in good agreement with those obtained by other investigators. A procedure similar to that employed by Goodling et al [13] was followed by Toit [8] to calculate experimentally the radial variation of porosity in a packed bed consisted of $3.6 \mathrm{~mm}$ lead balls at a bed of $50.4 \mathrm{~mm}$ in diameter. The experimental results were compared with those obtained from the analysis of numerically packed beds. The results show the same damped oscillatory behavior in the variation of porosity in the radial direction ranging from a maximum at the wall to the bulk value in the pebble bed center. Hassan et al. [18] used the particle tracking velocimetry (PIV) and refractive index matching techniques to present a flow structure in a pebble bed reactor. Mariani et al. [19] used a cylindrical bed (D are $10.72 \mathrm{~cm}$ and $6 \mathrm{~cm}$ ) packed with uniform size polypropylene spheres (d are $2.5 \mathrm{~cm}$ and $1.19 \mathrm{~cm}$ ). X-ray computed tomography (CT) was used to determine the position of each sphere center, then to evaluate the packing properties at local and global scales. Experimental results from two aspect ratios D/d (4.92 and 5.04) were analyzed and quantitatively compared to the simulated packed beds with a good agreement. Auwerda et al. [20] developed a non-destructive method using gamma-ray scanning to measure void fractions (absolute and radial void fraction profile) in a randomly stacked pebble bed ( $\mathrm{D}$ is $22.9 \mathrm{~cm}$, $\mathrm{d}$ is $1.27 \mathrm{~cm}$ and $\mathrm{D} / \mathrm{d}$ is 18.0 ). The results were used to validate three different computational tools. The radial void fraction profile showed large, 
dampened oscillations near the wall extending up to five pebble diameters into the pebble bed, with a minimum void fraction of 0.22 half a pebble diameter away from the wall. The computational methods generated the pebble beds with void fraction were in a good agreement with the experimental values. In all these studies small particles which are much smaller than the pebbles in PBRs (6 cm diameter) have been used. Hence, as mentioned earlier void distributions and bed structures with large particles close or similar to the size of pebbles used in PBRs have not been yet investigated experimentally.

Therefore, advanced imaging technique such as gamma-ray tomography with penetrating power to measure the cross-sectional and radial distribution holdup profiles of various sizes of the pebbles including large ones are needed to quantify the bed structure of the pebble beds. Tomography has found widespread applications in many scientific fields, including medicine, physics, chemistry, astronomy, geophysics, and engineering. Although X-ray computed tomography (CT) has a good spatial resolution in a small-scale object, it is not preferably used in industrial applications due to their lower energy and limited penetration. In contrast, gamma-ray tomography as a non-destructive and non-invasive technique is widely used in laboratory, pilot plants and industrial large scales and high-density units because of their higher energy and penetration power [21]. Usually, phase holdup distribution images are obtained by determining the attenuation values of the individual phases in the system by using gamma scanner and a suitable imaging reconstruction process.

Many gamma ray computed tomography (CT) experimental studies on bed structure characterizations and multiphase distributions have been reported during the last decades from different points of view and for various applications (Aboulwafa and Kendal [22], Harrison [23], Bowman [24], Kumar [25], Kumar et al., [26], Chaouki et al., [27], Roy [28], Chen et al., [29], Wang et al., [30], Rados [31], Roy et al., [32], Rados et al., [33], Hampel [34], Varma [35], Vasquez [36], AlMesfer [37] and Ahmed [38]). Gamma ray computed tomography has been successfully used to determine the radial void fraction of the packed bed reactors in general and pebble bed reactors in particular. Dijk [39] used an Am-241 gamma source tomography experiment to investigate the void fraction distribution and wall channeling effects in an acrylic cylinder with $30 \mathrm{~cm}$ height and 22.86 in diameter using a small pebble sizes $(12.7 \mathrm{~mm}$ and 3.18 mm). The facility used to be a scale down model of the HTR-10 which is currently active in China. Auwerda et al. [20] performed radial void fraction measurements in pebble bed reactor 
with cylinder to pebble diameter ratio $(\mathrm{D} / \mathrm{d}=18)$ using a computational tools and experimental gamma tomography to validate these tools. The results showed good agreement with the Discrete Elements Method (DEM) and expanding system method with the experiment for both average and radial void fraction.

It is obvious from the above that all the studies reported in the literature and derived correlations for void fraction prediction were performed using much smaller particle sizes than the size of the typical pebbles. This necessitates the need to conduct for the first time studies on quantifying the bed structure using relatively large particle sizes which is the focus of this study. Accordingly, in this work we have advanced the understanding of the pebble bed structure in terms of voids and solids cross-sectional distribution and radial profiles along the bed height using our dual energy-dual source computed tomography (DE-DSCT). The CT measurements will be first validated against phantom which represents multi-phase object. Furthermore, the experimental results obtained for the first time in this work using large particles will be used to quantify and to demonstrate the 3D image of the bed and the cross-sectional, axial and radial void fraction distributions.

\section{Experimental setup}

\section{Dual Source Computed Tomography (DSCT) Technique}

The DSCT scanner in the department of Chemical and Biological Engineering, Missouri University of Science and Technology at Professor Al-Dahhan's Lab "Multiphase Reactors Engineering and Applications Laboratory" (mReal) uses the newer generation of double fanbeam scanning configuration. The details of the hardware and software have been described in Vesvikar [40] and Varma [41]. A photograph of the CT technique used in this study is shown in Figure 4. The configuration of the scanner consists of two arrays of $\mathrm{NaI}(\mathrm{Tl})$ detectors of $5 \mathrm{~cm}$ in diameter (up to 15 detectors were used for each side depending on the column diameter to be covered) and two encapsulated sources $\sim 234 \mathrm{mCi}{ }^{137} \mathrm{Cs}$ (initially was $300 \mathrm{mCi}$ ) and $\sim 22 \mathrm{mCi}$ ${ }^{60} \mathrm{Co}$ (initially was $50 \mathrm{mCi}$ ) located opposite to the center of the each array of detectors, placed $120 \mathrm{~cm}$ apart. In this study, only the ${ }^{137} \mathrm{Cs}$ source is used since two phases (solid and air) were used. The detectors and the source are mounted on a plate which can be rotated $360^{\circ}$ around the object to perform the measurements at a sampling frequency that can be up to $50 \mathrm{~Hz}$. Hence, the measurement of this technique is a time averaged measurement. Moreover, the whole assembly can be moved up and down along the column to scan different axial levels of the column to 
provide three dimensional (3D) imaging of the bed. Each of these detectors is collimated with a lead collimator that is about $6.35 \mathrm{~cm}$ thick and has an open aperture of dimension $2 \mathrm{~mm} \times 5 \mathrm{~mm}$ (which can be changed depending on the desired resolution). This aperture reduces the effective exposed area of the crystal to a rectangular region of dimension $2 \mathrm{~mm} \times 5 \mathrm{~mm}$. The counts received by the detectors are limited to what is incident on this aperture. This detector array is moved with a stepper motor 21 times at an angle of $0.13^{\circ}$ from the source, thereby creating 315 detector positions effectively for each source position. The projection is modeled as a fine line between the source and the detector as the open area of the detectors is very small. A total of 197 views or source positions are considered; hence, gamma ray counts data for $315 \times 197$ (total 62055) projections passing through the domain are collected. The gamma ray counts data recorded are energy threshold; hence, un-attenuated gamma ray photon counts of $660 \mathrm{keV}$ were recorded. A $100 \times 100$ pixels resolution is used to reconstruct the image. Hence, each pixel represents an area of $2 \mathrm{~mm} \times 2 \mathrm{~mm}$ of the object.

The reactor set-up, shown in Figure 2, is made of Plexiglas with outside diameter of $30.48 \mathrm{~cm}$ (12 in.) and a height of $30.48 \mathrm{~cm}$ (12 in.). The solids used in this study were glass spheres (Marbles) with three different mean diameters of $(1.27 \mathrm{~cm}, 2.54 \mathrm{~cm}$ and $5 \mathrm{~cm}$ respectively) and a density of $2.5 \mathrm{~g} / \mathrm{cc}$, randomly packed inside the column. The $5 \mathrm{~cm}$ sphere's diameter was selected due to its availability which is closer to the actual pebble size $(6 \mathrm{~cm})$ used in PBRs. The smaller pebble sizes were selected to provide the variation in the void structure obtained with different particle sizes. In the present study, three axial levels have been scanned at heights of $7.62 \mathrm{~cm}, 15.24 \mathrm{~cm}$ and $22.86 \mathrm{~cm}$ from the base of the bed. These heights represents the lower part, bulk region (center), and the upper part of the bed to assess the possible variation if any in void distributions with the changes of axial heights. The data acquisition system consists of the detectors, preamplifier, pulse processors and stepper motors that automate the motions involved in the CT system. The system can perform the measurement at a wide range of sampling rate depending on the dynamic, the type and the size of the object to be imaged (up to $50 \mathrm{~Hz}$ ). The solid state scintillation detectors (made by Bicron) were used in the experiments. Each detector assembly consisting of a $2 " \times 2 " \mathrm{NaI}(\mathrm{Tl})$ crystal in an aluminum housing, a photomultiplier tube directly mounted to crystal housing, an internal magnetic/light shield followed by preamplifier (see Figure 3). A 2" $\times 2$ " crystal has about $70 \%$ absorption efficiency for ${ }^{137} \mathrm{Cs}$ source and the best resolution achievable ranges from $7.5 \%-8.5 \%$ for $662 \mathrm{KeV}$ gamma ray 
[42]. The Canberra preamplifier Model 2007 was used. The preamplifier is connected directly to the photomultiplier tube (PMT) containing a high voltage divider network to supply voltage for the PMT and the Anode output signal. The signal from the preamplifier, attached to the detector, is fed to the timing amplifier. This is in turn passed on the multilevel discriminator and a scalar. The final data is stored in the computer in form of a data file. A photograph of the timing amplifier and the crate controller computer are shown in Figure 4.

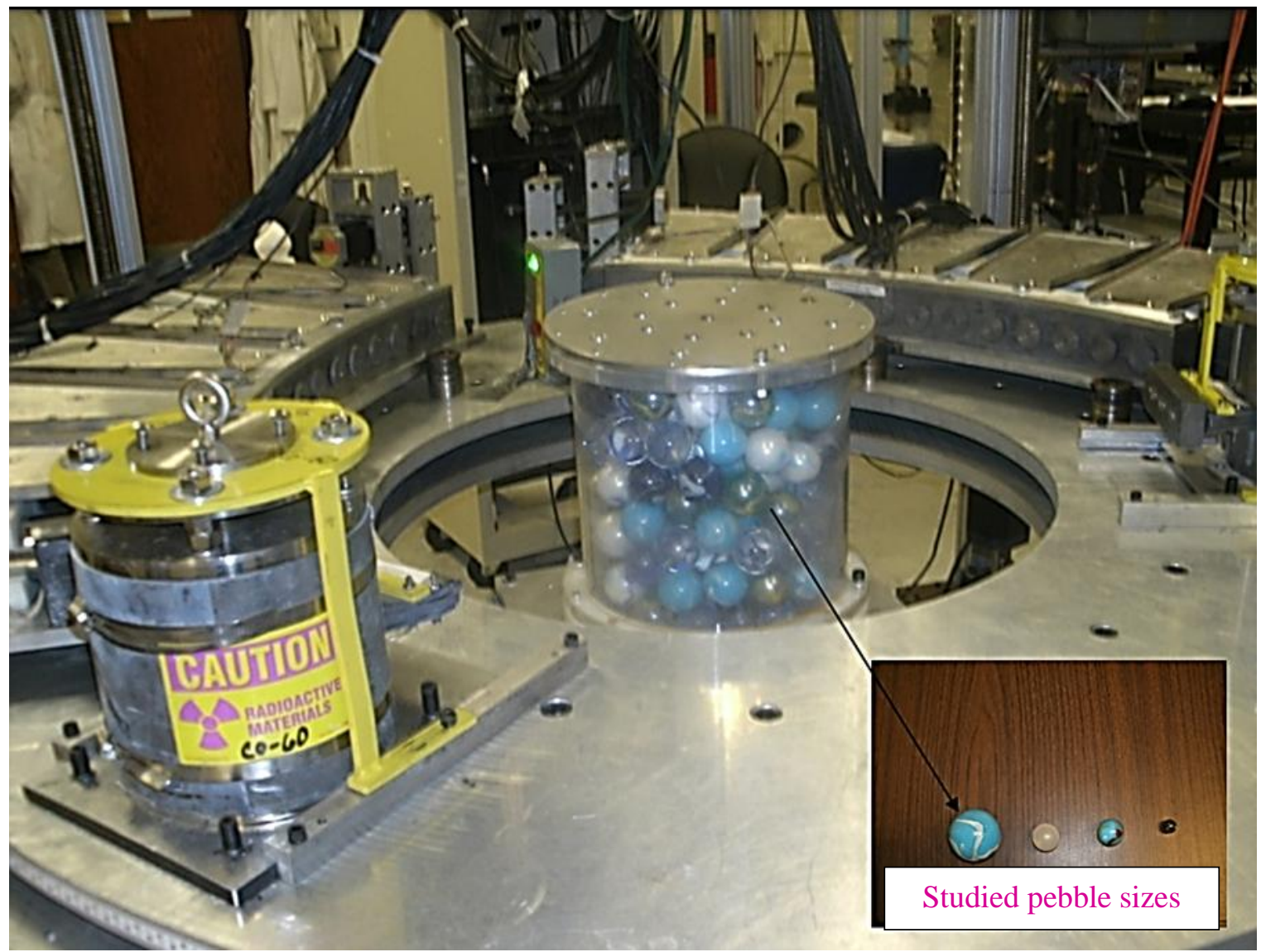

Figure 2: A photograph of the DSCT technique with a $0.3 \mathrm{~m}$ setup pebble bed reactor of $0.3 \mathrm{~m}$ height packed with a $0.05 \mathrm{~m}$ pebbles. Other studied pebble sizes were $0.0127 \mathrm{~m}$ and $0.0254 \mathrm{~m}$ 


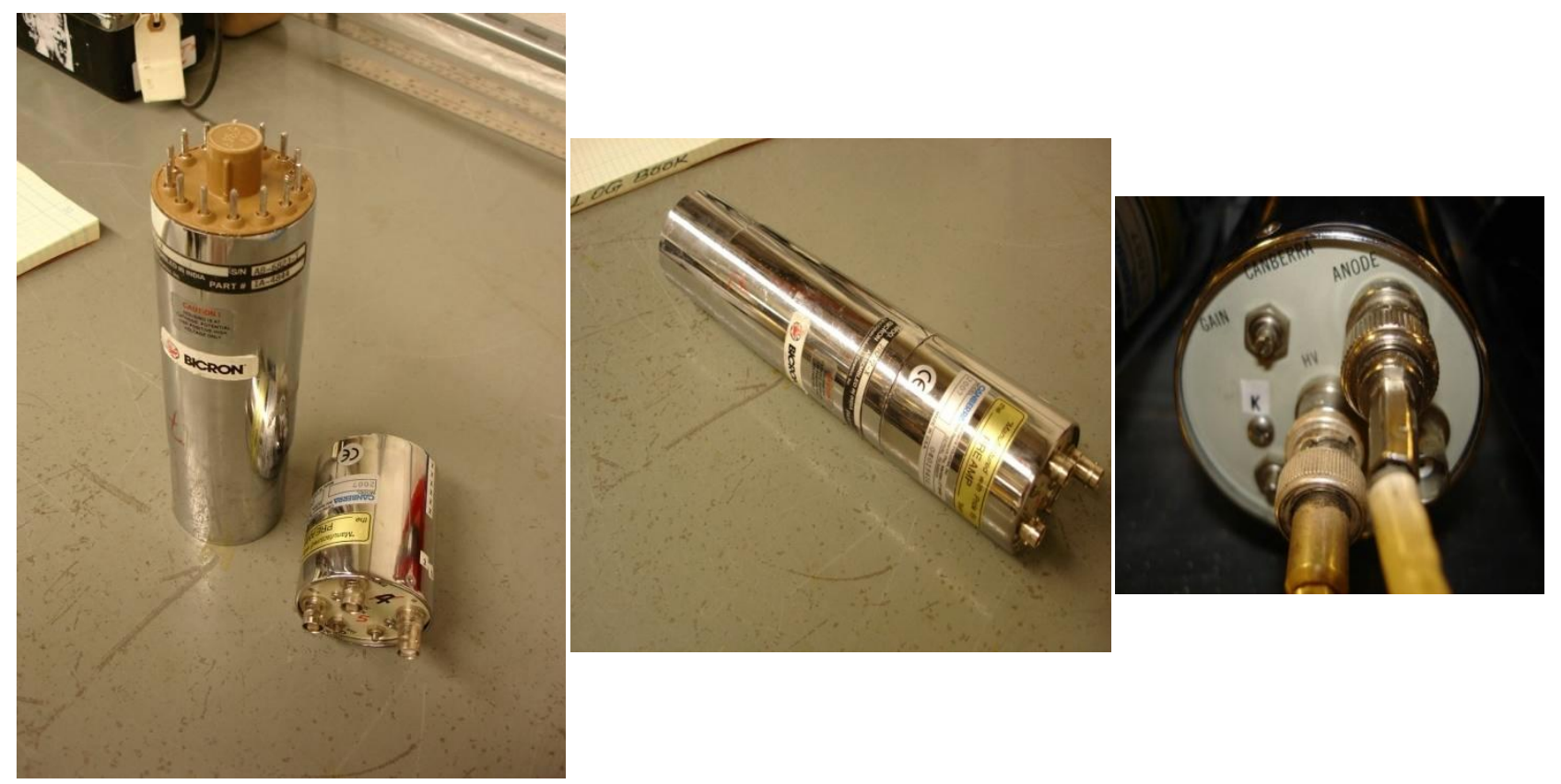

Figure 3: The $\mathrm{NaI}(\mathrm{Tl})$ solid state scintillation detector assembly

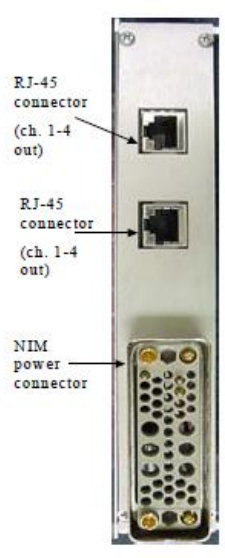

Rear panel
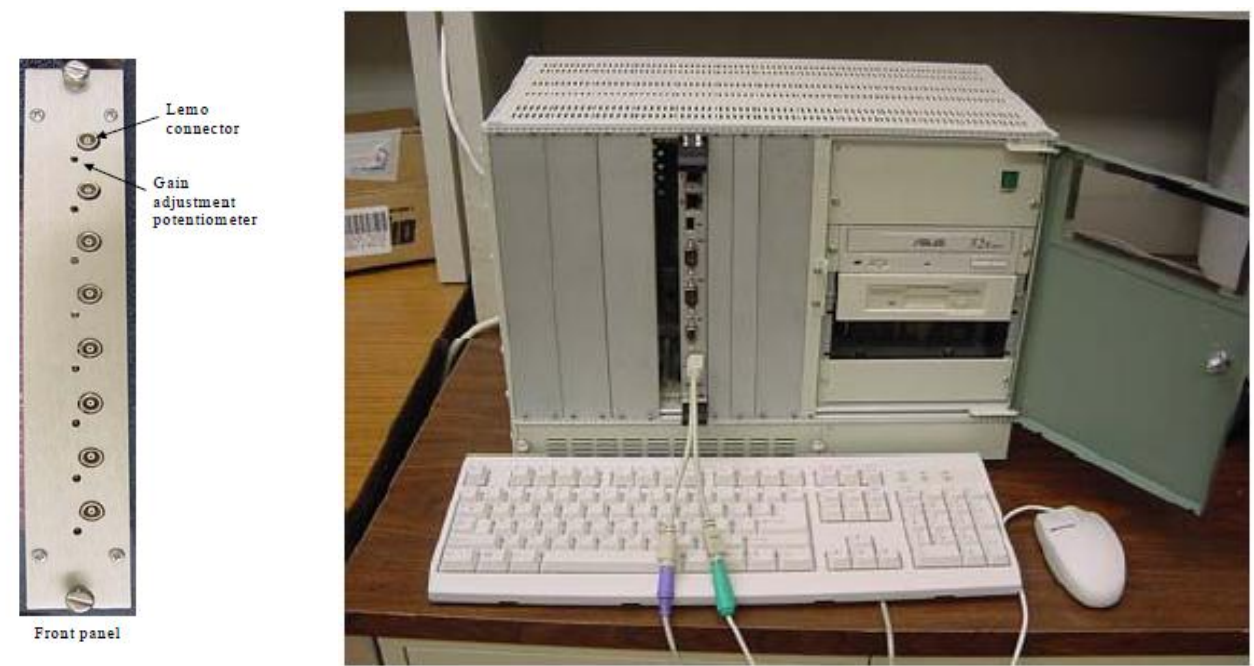

Figure 4: Shaping amplifier module (left) and the crate controller and single board computer (right)

The electronic modules associated with the NIM bin crate and the PCI crate was developed at the Oakridge National Laboratory (ORNL). A C++ based program called Biomass.c developed by ORNL was used to perform the CT scan and to acquiring the data. Details of the data acquisition modules and the operation of Biomass.c have been discussed in Vesvikar [40]. 


\section{Image Reconstruction}

The reconstruction of the attenuation coefficients image from the raw scanned data is obtained in a stepwise process. It involves: Averaging the raw data, calculating the transmission ratios, geometry input data - Calculating the length of the chords for each projection, assigning initial guess, image reconstruction using iterative algorithm, calculating the phase holdups and averaging and plotting data. In each step, a corresponding code is used.

The domain of the cross section of the bed is divided into $100 \times 100$ pixels. Alternating Minimization (AM) algorithm [43] has been used to reconstruct the time averaged image of the attenuation coefficient in each pixel. The image reconstruction algorithm is based on a statistical model for the measured data, Beer-Lambert's law and a realistic model for the known point spread function. The reconstruction problem is formulated as an optimization (maximum likelihood) problem.

\subsection{CALCULATION OF THE PHASE HOLDUP}

The first step in obtaining holdup distribution profile is to obtain the attenuation image from the raw scanned data using AM image reconstruction algorithm. The attenuation coefficient $(\mu)$ of any object is quantified in terms of Beer-Lambert's law:

$I=I_{o} \cdot \exp (-\mu \cdot l)$

where, in general, $I_{o}$ is the incident radiation and $I$ is the detected radiation intensity after passing through length $l[\mathrm{~cm}]$ of object whose linear gamma-ray attenuation coefficient is $\mu\left(\mathrm{cm}^{-1}\right)$. This equation is used to obtain the attenuation values from the transmission ratio. The value of $l$ is calculated based on the geometry of CT scanner and the dimension of the scanned object.

If the medium is made of two materials (such as solid and gas in this case) with mass attenuation coefficients $\mu_{s}$ for solid and $\mu_{g}$ for gas, densities $\rho_{s}$ for solid and $\rho_{g}$ for gas, and thickness $l_{s}$ for solid and $l_{g}$ for gas, then the total attenuation $A$ is

$A=\rho_{s} \mu_{s} l_{s}+\rho_{g} \mu_{g} l_{g}$

Since $l_{s}=\varepsilon_{s} L$ and $l_{g}=\varepsilon_{g} L$, where $L=l_{s}+l_{g}$ then

$A=\left[\rho_{s} \mu_{s} \varepsilon_{s}+\rho_{g} \mu_{g} \varepsilon_{g}\right] L$

The summation of the holdups equals unity (i.e. $\varepsilon_{g}=1-\varepsilon_{s}$ ) then Eq. 3 become

$A=\left[\rho_{s} \mu_{s} \varepsilon_{s}+\rho_{g} \mu_{g}\left(1-\varepsilon_{s}\right)\right] L$.

The measured quantity $\ln (I / I o)$ is equal to the integral sum of the attenuation through the material along the beam path (i.e., sum the attenuation in pixels along the beam path). For 
tomography, attenuations are measured along a number of such beam paths through the object from different directions around it. Given a set of attenuation measurements, the density distribution (image) in each pixel of the $100 \times 100$ pixels domain can be reconstructed by using a suitable reconstruction algorithm. In the present study, an Alternating Minimization (AM) algorithm is being used to quantitatively estimate the attenuation coefficient distribution images of the packed bed packed with marbles (glass) pebbles. Since the medium in the $i j^{\text {th }}$ pixel is made of two materials, then the total line attenuation $A_{s-g, i j}$, can be written as

$A_{s-g, i j}=\left[\rho_{s} \mu_{s} \varepsilon_{s, i j}+\rho_{g} \mu_{g}\left(1-\varepsilon_{s, i j}\right)\right] L_{i j}$

where $\varepsilon_{s, i j}$ and $\varepsilon_{g, i j}$ are the holdups (volumetric fractions) of the solid and gas phases respectively, and $L_{i j}$, is the length along which a particular gamma ray beam passes through the pixel. Since $\rho_{g}<<\rho_{s}$, the attenuation caused by the gas phase is negligible $\left(\mu_{g}=0\right)$, and $L_{i j}$ is common for all $A$ 's in a single pixel. Hence, solids holdup in pixel $i j$ can be written as follows $\varepsilon_{s, i j}=A_{s-g, i j} / \rho_{s} \mu_{s}$

The mass attenuation values obtained by using the reconstruction program for the packed solids can directly be used in place of $A_{s-g, i j}$. The linear attenuation coefficient of solids $\left(\mu_{s}\right)$ was calculated experimentally by using the CT scan setup as a gamma-ray densitometry device and applying the Beer Lambert's Law to measure the attenuation $\mu$ for one marble ball attached to the detector collimator. The $\mu$ can also be determined by using standard tables (such as NIST Physical Data) if the material composition of solids is precisely known. Finally, the void fraction distribution was determined using the expression

$\varepsilon_{g, i j}=1-\left(A_{s-g, i j} / \rho_{s} \mu_{s}\right)$

The time averaged cross-sectional solids and voids profiles can be represented in two ways. A color contour plot is used as part of the first method to plot the cross-sectional distribution of different phases. The second method is based on the circumferentially averaged the pixels of the cross sectional distribution. The following equation is then applied so that the result can be plotted as averaged radial variation of the void fraction:

$$
\bar{\varepsilon}=\frac{2}{R^{2}} \int_{0}^{R} \varepsilon(r) r d r
$$

Where $R$ is the radius of the column and $r$ is the radial position.

The main focus of this work is to quantify the void and solids holdup distribution across the two dimensional domain in randomly packed pebble beds. Several, CT scans were performed 
at specific conditions so that sufficient data for holdup calculations (e.g., scan with air only between the source and the detector and scan for the packed bed) could be collected. The algebraic algorithm of Alternating Minimization (AM) was applied to determine the attenuation coefficient values $(\mu)$ in the pixels of the domain. The linear attenuation coefficient in each pixel was verified for gas and solids phases. One hundred pixels were chosen in the image reconstruction process where the special resolution for these experiments was $2 \mathrm{~mm}$. In the subsequent sections the measurements of the void fraction and solids distribution in a pebble bed reactor were presented. The radial distribution profiles of the void fraction within the pebble bed were also obtained along with the void probability distribution. These measurements as mentioned earlier are time averaged measurements, however, since the bed of pebbles is static (stationary), the results are presented without mentioning that they are time averaged.

\subsection{CT-SCAN SYSTEM VALIDATION}

Since the measurements of the received radiation spectrum and its photo-peaks drift, multichannel analyzer (MCA) needs to be used to adjust and align all the signals and photopeaks of all the detectors which affect the CT measurements if this step is not done properly. Therefore, before conducting the experiments of CT tomography in the pebble bed reactor, it is advisable to assess the CT scan measurements of the time averaged phase density distribution by using test phantoms which are designed to represent multi-phase system in order to ensure that the signal adjustment has been done properly. The test phantom used in this study is made of Perspex with a resolution of 80 x 80 pixels. The phantom represents a circular domain of 15.24 $\mathrm{cm}$ (6 inch) diameter consisting of two sections; the inner section is a tube with $7.1 \mathrm{~cm}(2.79$ inch) inside diameter which is filled with air. The outer section is filled with water and has inner diameter of $13.9 \mathrm{~cm}$ (5.47 inches). In this experiment the attenuation images were obtained by determining the background scans where the domain purely consists of only one phase (such as air as the gas phase) and another scan for the two phases (liquid-air). The averaged data from the CT scan files for water-air phases, along with the data file for air only were used to calculate the transmission ratio $\left(\mathrm{I} / \mathrm{I}_{0}\right)$ of the scanned phantom. Figure $(5-\mathrm{a})$ shows a typical transmission ratio plot for the $15.24 \mathrm{~cm}$ phantom. The plot illustrates smooth and symmetric along the center. It is always advisable to make such a plot as an intermediate step in the reconstruction process to assess the correctness and quality of the scan. The sinogram tool has been implemented in this study to visualize the attenuation values for all positions of source and detectors. Sinogram 
image shown in Figure (5-b) was reconstructed using the transmission calculated from the measured counts. Each pixel in the sinogram represents the transmission ratio for the corresponding projection number given.
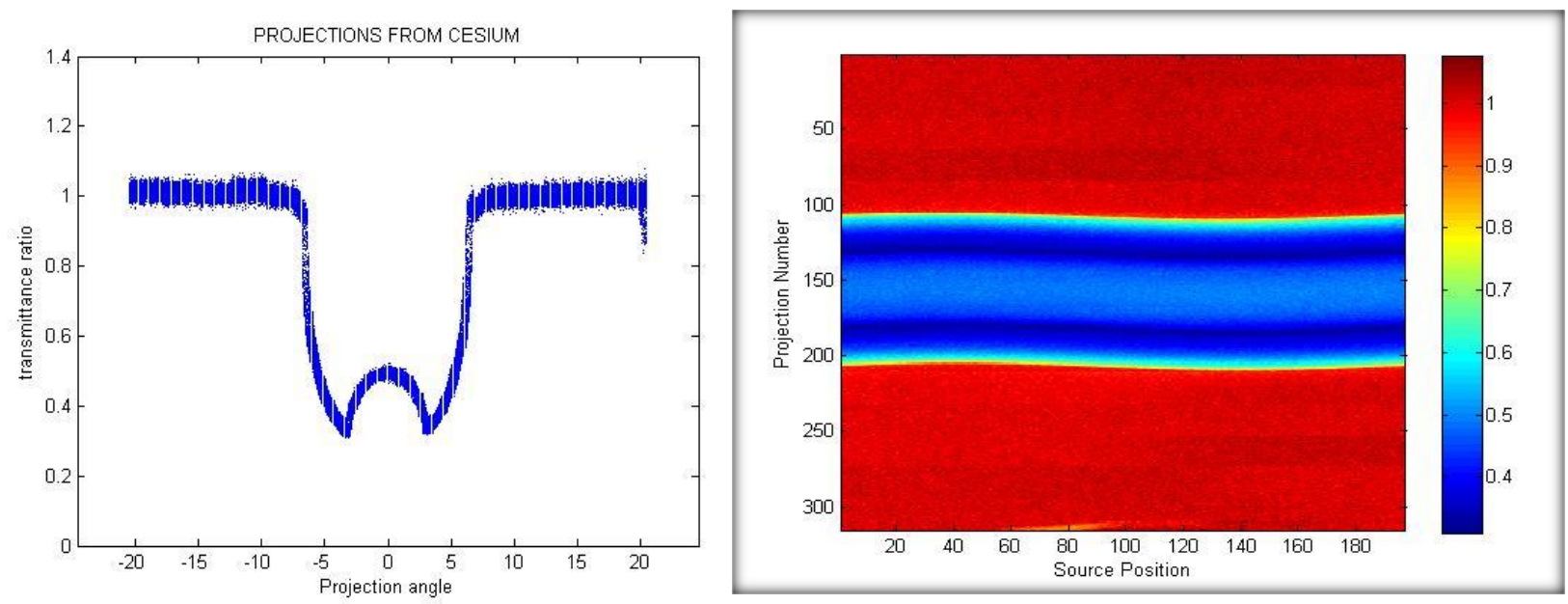

a

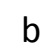

Figure 5: (a) the transmission ratio $\left(\mathrm{I} / \mathrm{I}_{0}\right)$ for the phantom (b) The Sinogram of the phantom attenuation coefficients

The alternating minimization (AM) algorithm [43] was employed to process the CT scanner data and to reconstruct and validate the phantom data. The mean attenuation values obtained from AM algorithm showed that the attenuation image of the scanned domain matched closely the theoretical values for water and air attenuation coefficients of $0.0857 \mathrm{~cm}^{-1}$ and 0.001 $\mathrm{cm}^{-1}$, respectively (Figure 6). The discrepancy between the actual phantom's dimensions and the obtained dimensions from the CT scan can be found in the error analysis section. 


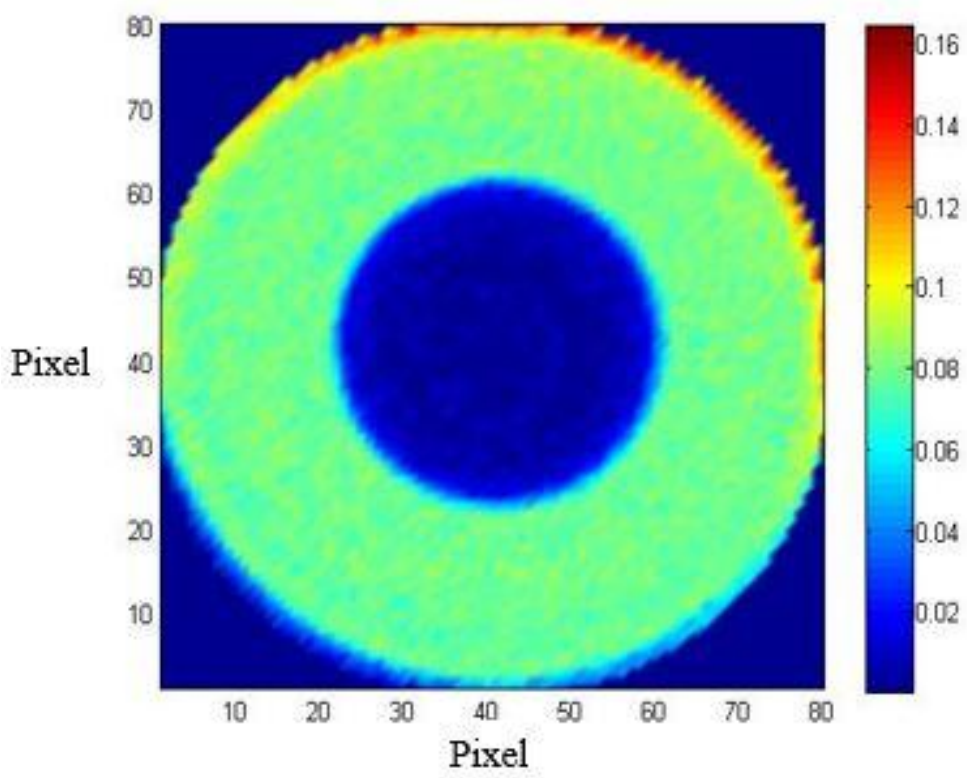

Figure 6: The mass attenuation coefficient distribution for the two phase (air-water) phantom (AM image reconstruction)

\section{ERROR ANALYSIS}

There are always errors in any measurement and there is no physical quantity which can be measured with perfect certainty. A good measurement must be close to the true value and be reproducible. In order to test the precision of the gamma ray tomography (CT) experimental data and to test the quality of the experimental measurements, an error analysis and the reproducible of the measurements have been made to the CT experimental data as follows.

\subsection{THE ACCURACY OF THE EXPERIMENTAL RESULTS}

In this analysis an exact dimensions of the phantom used in the validation section was measured. As shown in Figure 7, the inner section diameter was $7.1 \mathrm{~cm}$ with air only and the outer section diameter was $13.9 \mathrm{~cm}$ filled with water. The values of their linear attenuation coefficients were compared to those obtained from the CT scan experiment using the AM reconstruction algorithm. The number of pixels used in the alternating minimization (AM) algorithm was 80x80 pixels. The dimensions of each pixel is $0.19 \times 0.19 \mathrm{~cm}$. The number of pixels of the air phase in the inner section was 38 pixels $(7.22 \mathrm{~cm})$ with a percentage difference of $1.69 \%$ compared to the exact phantom's dimensions. 


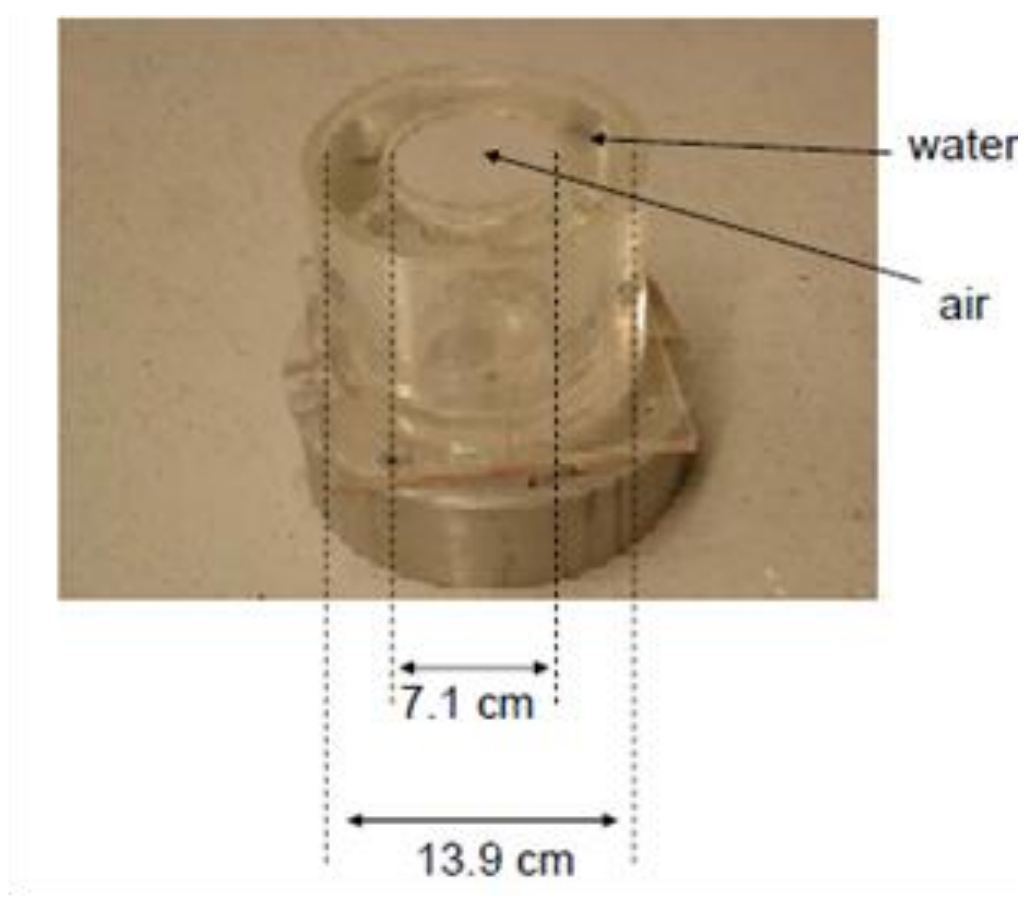

Figure 7: Picture of the 6" phantom (Perspex) used in the CT scan experiments with two phases (air in the inner section and water in the outer section)

\subsection{THE REPRODUCIBILITY OF THE MEASUREMENTS}

In this section, the CT scan at the middle of the pebble bed height was repeated two times for reproducibility assessment. The azimuthally time averaged radial void fraction profiles of a bed packed with $5 \mathrm{~cm}$ in diameter pebbles were measured twice. For each data point at the radial profile, the average and the difference percentage were calculated. Errors for each data point were expressed in graph by using percentage difference bars (see Figure 8). It has been shown that the new measurements were very close to the old measurements with average percentage difference of $1.71 \%$. Since the percentage differences are inconsiderable value, these errors will not be indicated for the rest of the data presented in the following graphs. 


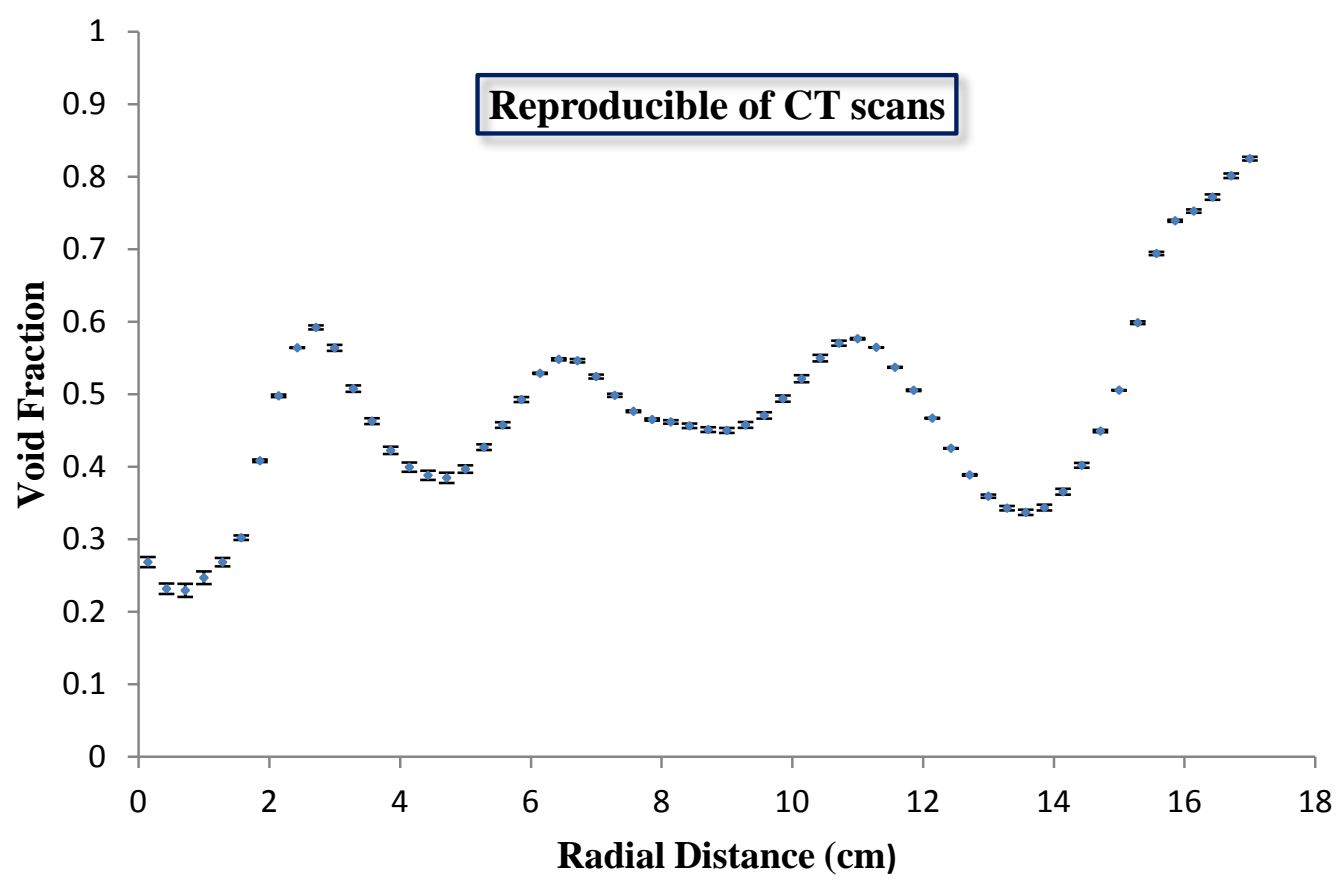

Figure 8: Azimuthally averaged radial void fraction profiles at the bed center (axial level $=15.24$ $\mathrm{cm}$ ) were repeated twice for reproducibility. The bars reflect the percentage difference between the two measurements.

\section{Results and discussion}

All experiments were conducted in a $0.3 \mathrm{~m}$ diameter and $0.3 \mathrm{~m}$ height column that was packed randomly with glass spheres of different sizes $(0.0127 \mathrm{~m}, 0.0254 \mathrm{~m}$ and $0.05 \mathrm{~m})$. Additional measurements were made by adding additional height of pebbles on the top of the original one of $0.3 \mathrm{~m}$ to examine the effect of additional load on the results.

\subsection{VOID FRACTION DISTRIBUTION IN PEBBLE BED REACTOR}

Figure 9 shows the cross-sectional (spatial) void fraction distribution of the pebble bed of $0.3 \mathrm{~m}$ diameter at different pebble sizes $(0.0127 \mathrm{~m}, 0.0254 \mathrm{~m}$ and $0.05 \mathrm{~m}$ respectively) at the bulk region (middle section of the bed at $0.1524 \mathrm{~m}$ from the base). As shown in this figure, the gamma ray tomography technique provided a clear graphical representation of the different phase distributions that occurred in cross-sections of the packed pebble bed column. The pixels with red level values are directly related to the highest void fraction at that specific condition. Several pockets (blue areas) of high porosity zones occurred within the pebble bed's distribution. 
Histograms were used to further analyze the void distribution images. These histograms were generated from the experimental data gathered; they were used to quantify the void variations. The probability distribution conformed to a normal distribution pattern in all three of the packing sizes. The void distribution was strongly depend on the pebble size or the aspect ratio $\left(\mathrm{D}_{\text {column }} / \mathrm{d}_{\text {particle }}\right)$. When the pebble's diameters increased from1.27 $\mathrm{cm}(0.5 \mathrm{inch}, \mathrm{D} / \mathrm{d}=24)$ to 2.5 $\mathrm{cm}$ ( 1 inch, $\mathrm{D} / \mathrm{d}=12$ ), the variance of void increased by $2.3 \%$. The void's spreading increased by $198 \%$ when the pebble's diameter increased from $2.5 \mathrm{~cm}(1 \mathrm{inch})$ to $5 \mathrm{~cm}(2$ inches, $\mathrm{D} / \mathrm{d}=6)$. The void fraction was relatively higher near the wall and lower in the center.
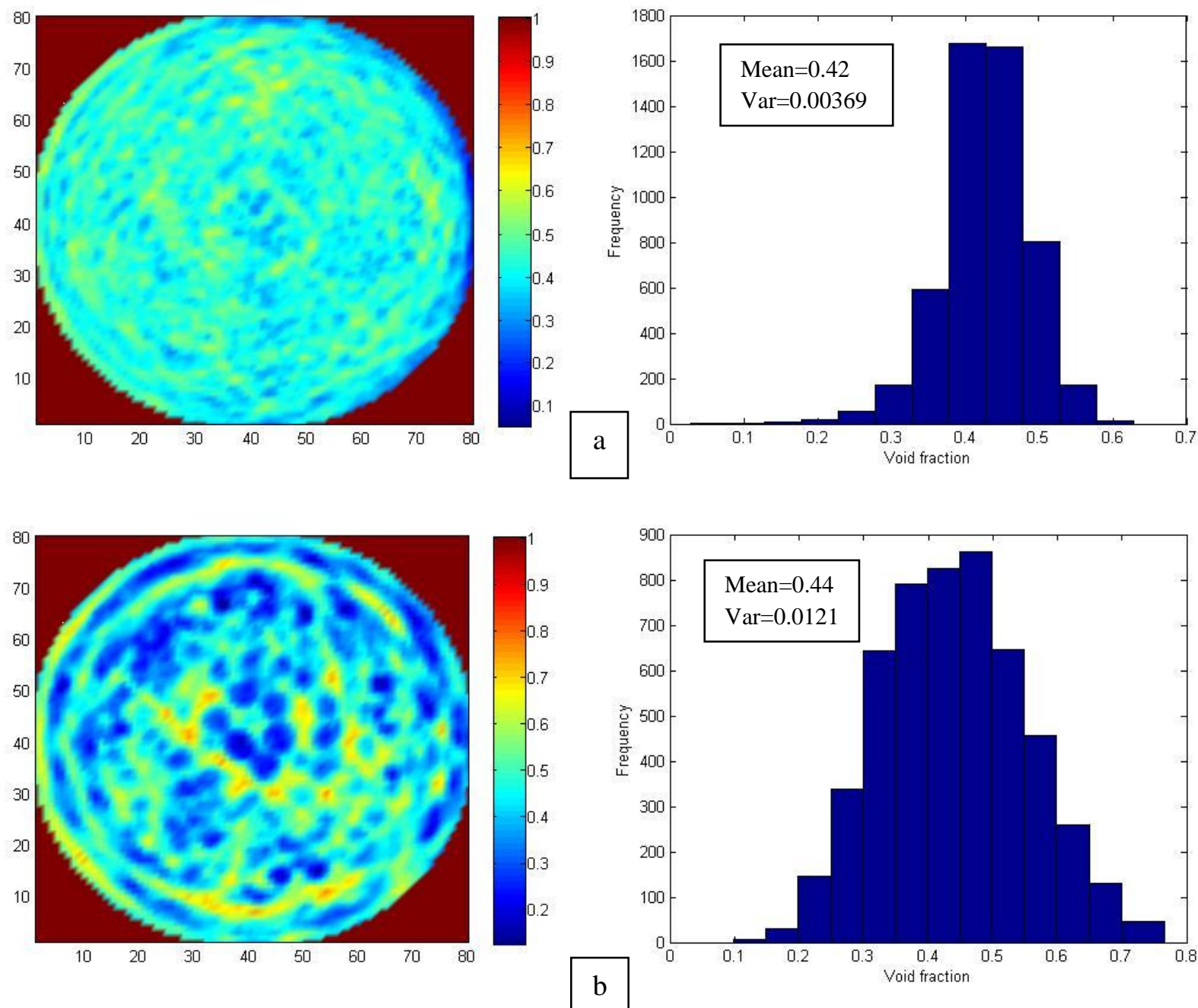

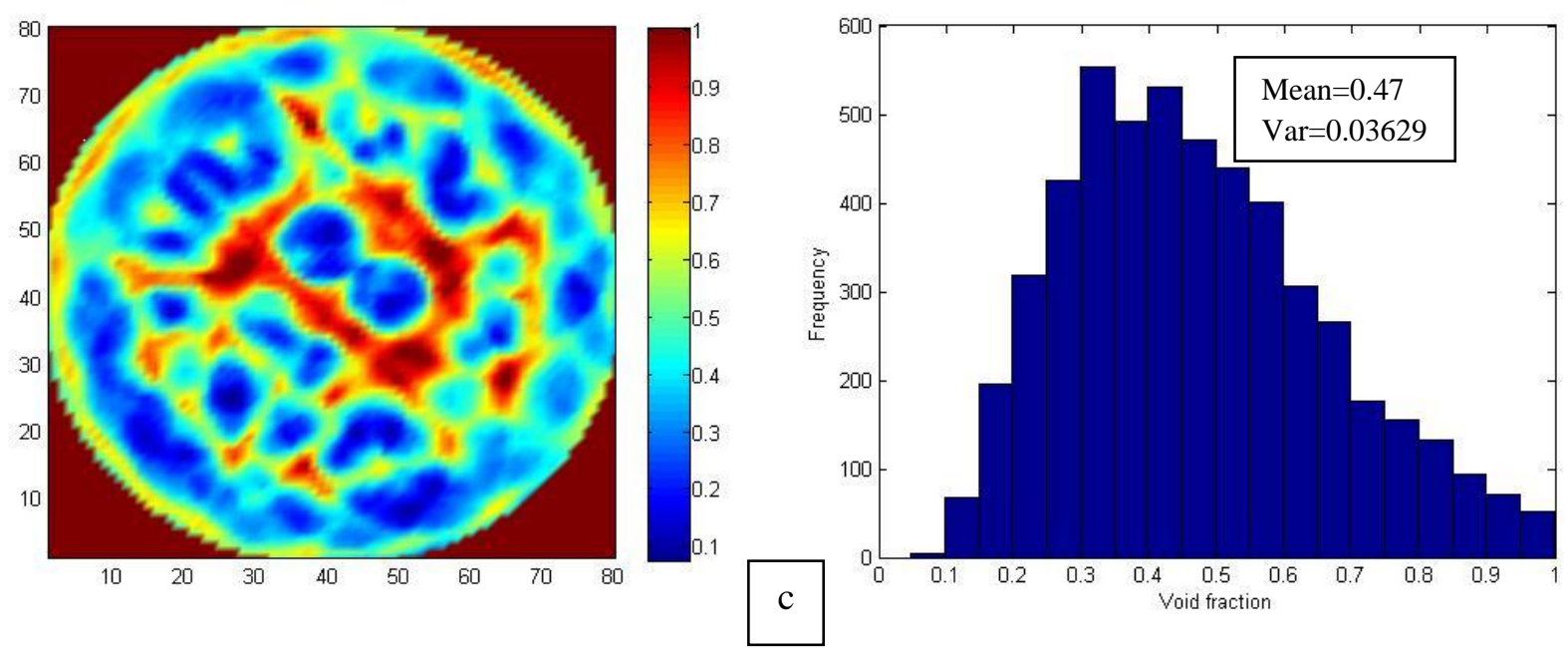

Figure 9: Spatial cross-sectional void fraction distributions and histograms (population distribution function) of the local void distributions at the pebble bed's middle section (0.1524 $\mathrm{m}$ from the base) using $0.3 \mathrm{~m}$ diameter column with pebble sizes of (a) 0.0127 $\mathrm{m}$, (b) $0.0254 \mathrm{~m}$, and (c) $0.05 \mathrm{~m}$.

\subsection{AVERAGED RADIAL PROFILES OF THE VOID DISTRIBUTION}

The radial void variation is another characteristic structural feature of confined fixed packed beds. It is produced by the influence of column walls [44]. Both axial and radial porosity (void) variations have a strong influence on the fluid's flow. Hence, they also influence the heat and mass transfer present in the fixed-bed reactors. The azimuthally averaged radial void distribution profiles for the three different pebble diameters at different axial levels of the pebble bed of $0.3 \mathrm{~m}$ diameter are given in Figure 10. The oscillations are quite large near the wall, with a minimum void fraction of 0.33 at a $0.68 \mathrm{~d}$ ( 0.68 pebble diameter) from the wall (for $0.05 \mathrm{~m}$ pebble size).

One would expect the void fraction would to go to unity near the wall, since the solids have point contacts at the walls. However, less than 1.0 (0.85) was estimated at the pixels close to the wall. This less than unity of void fraction would have been caused by the gamma ray attenuation that occurred within the region of the column wall itself where the projections that pass through the solids around the contact points cause more attenuation in the pixels near the wall region. Hence, this is a characteristic inherited in applying image reconstruction of the gamma ray CT by measuring the attenuation through the projections. Accordingly, the pixels of the pebble contact points will not give a void fraction $(\mathcal{E})$ equal to 1.0 since in that pixel there are solids seen along other angels of gamma ray projections when the CT scanner rotate $360^{\circ}$ around 
the bed. Thus, the pixels used for image reconstruction at the wall would provide lower than 1.0 void fractions. In general, the gamma sampling volume was too small to clearly capture the void within one particle size and the contact points of the particles at the wall in order to give void fraction of unity [from 19 and 30].

Several pockets of voids occurred near the center of the pebble bed as a result of the random packing process. Thus, the trend exhibited a slight rise in the void fraction. Due to large local void volume obtained with relatively large size pebbles $(>2.5 \mathrm{~cm})$ and the structural inhomogeneities of such randomly packed pebbles, different heights of CT scans give varying trends of the radial porosity profiles and its oscillation. In our work, the measured radial void fraction profiles had similar oscillating trends from the wall as compared to the recent literatures for the cylindrical packed systems with different ratios of column diameter to sphere diameter $[13,36$, and 45].

However, due to wall effect $(\mathrm{D} / \mathrm{d}=6$ and $\mathrm{D} / \mathrm{d}=12)$ the void radial profiles of the pebbles of $0.05 \mathrm{~m}$ and $0.0254 \mathrm{~m}$, respectively are fluctuated toward the bed center and they are not stabilized as compared to that of pebble of $0.0127 \mathrm{~m}$ of $\mathrm{D} / \mathrm{d}=24$. The fluctuations of the void radial profile of the bed with $0.05 \mathrm{~m}$ pebble diameter $(\mathrm{D} / \mathrm{d}=6)$ is noticeably higher than that of the $0.0254 \mathrm{~m}$ pebbles diameter. This is a new finding since our work is the first of its kind to study the bed structure of large size pebbles using gamma ray computed tomography (CT).

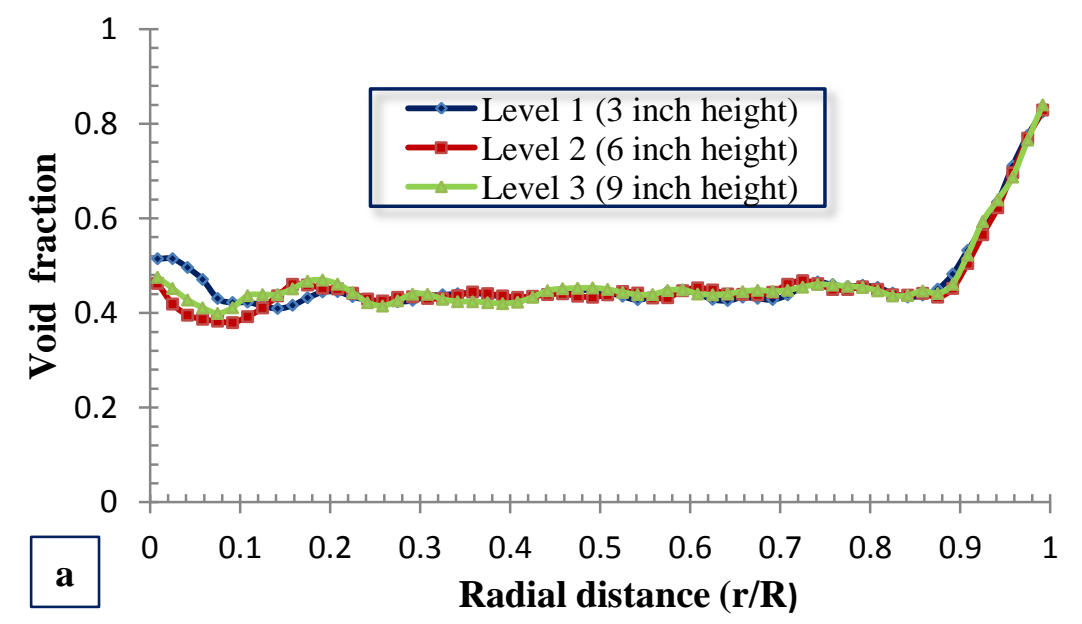



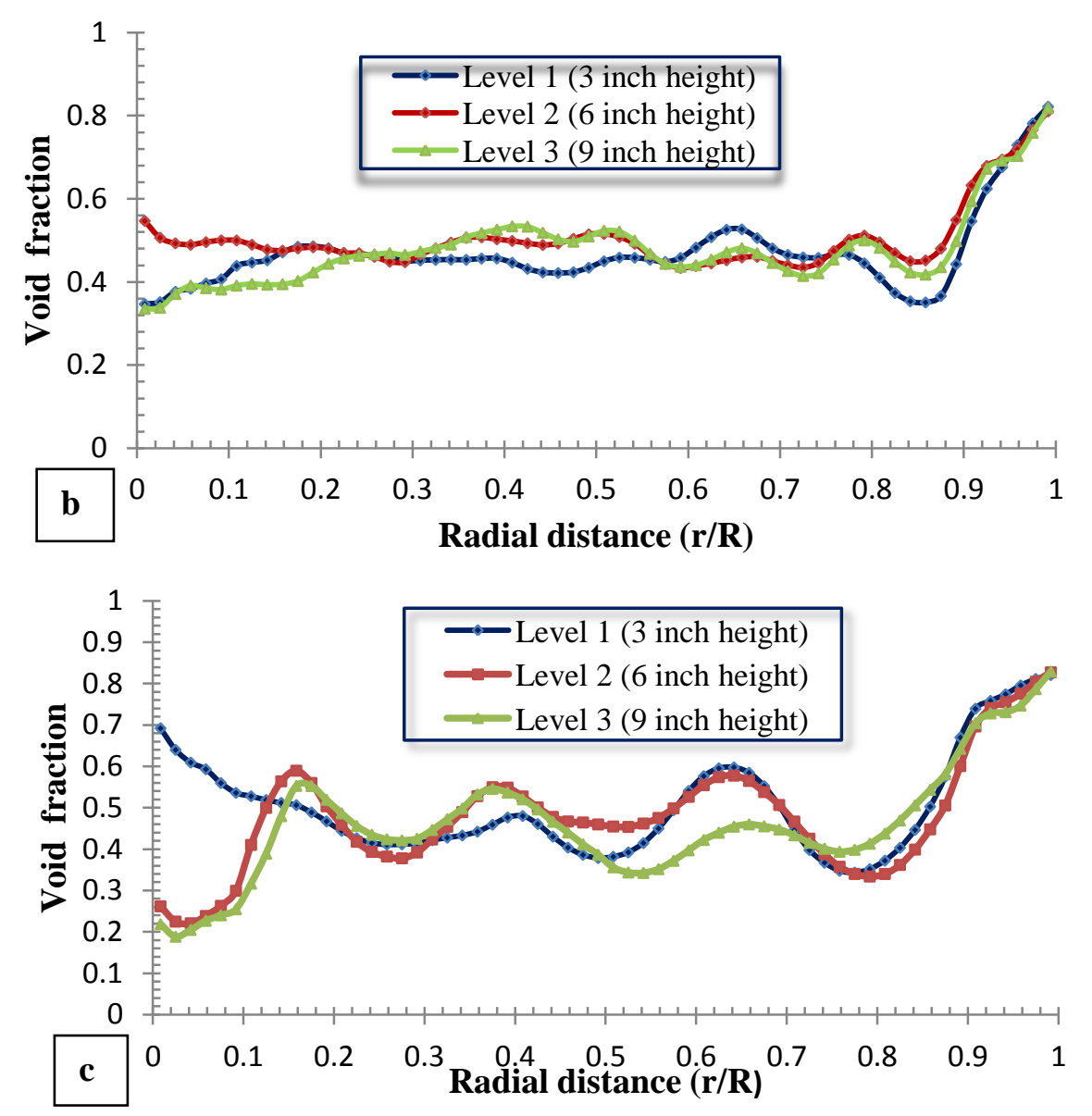

Figure 10: Azimuthally averaged radial void fraction profiles for the three different pebble diameters a: $\left(\mathrm{d}_{1}=0.0127 \mathrm{~m}, \mathrm{D} / \mathrm{d}=24\right), \mathrm{b}:\left(\mathrm{d}_{2}=0.0254 \mathrm{~m}, \mathrm{D} / \mathrm{d}=12\right)$ and $\mathrm{c}:\left(\mathrm{d}_{3}=0.05 \mathrm{~m}\right.$,

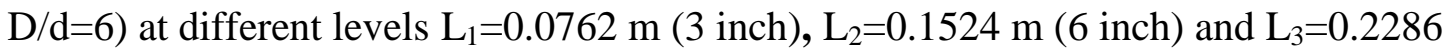
$\mathrm{m}$ (9 inch)

\subsection{EFFECTS OF PEBBLE SIZE AND BED HEIGHT ON AZIMUTHALLY TIME AVERAGED RADIAL PROFILES OF THE VOID DISTRIBUTION}

\section{a) Effects of pebbles size on void distribution}

The azimuthally averaged radial void profiles for the three pebble diameters $(1.27 \mathrm{~cm}$, $2.54 \mathrm{~cm}$ and $5 \mathrm{~cm}$ ), at the bulk region of the pebble bed (center height of the bed) are depicted in Figure 11. The radial profile for the $5 \mathrm{~cm}$ pebble oscillated strongly from the wall toward the bed's center because these sizes of pebbles provided larger local void volumes. Smaller pebble sizes $(1.27 \mathrm{~cm})$ oscillated less than the other two larger diameters pebbles. The smaller pebble's radial void fraction profile, with a minimum void fraction of 0.43 , was almost 4 pebble diameters away from the wall; while it was 0.37 at less than 1 pebble diameter with a $0.0254 \mathrm{~m}$ pebble size and 0.33 at a half pebble diameter with a lager pebble size $(0.05 \mathrm{~m})$. The void fraction fluctuated 
around the mean, with a lower value (0.27), near the center of the packed bed and a higher value at the wall region (0.85); see Figure 11.

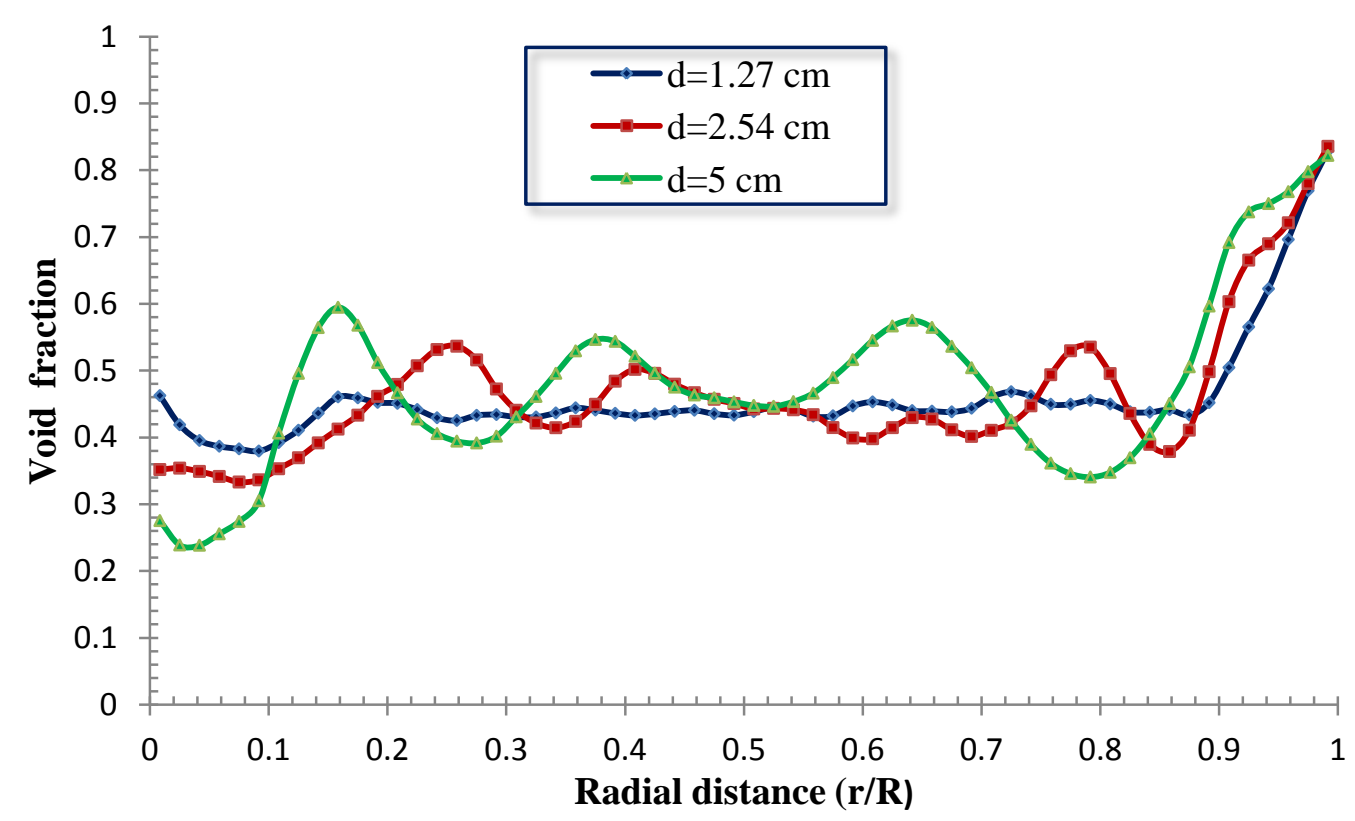

Figure 11: Azimuthally averaged radial void fraction profiles for the three different pebble diameters $(\mathrm{d}=1.27 \mathrm{~cm}, \mathrm{~d} / \mathrm{D}=24 ; 2.54 \mathrm{~cm}, \mathrm{~d} / \mathrm{D}=12$ and $5 \mathrm{~cm}, \mathrm{~d} / \mathrm{D}=6)$ at the bulk region level (center of the bed height of 6 inch from the base)

\section{b) Reproducibility of the packing method (i.e., repacking)}

The pebble bed reactor analyzed in this experiment consisted of a $0.3048 \mathrm{~m}$ high Plexiglas column that was packed with $0.0254 \mathrm{~m}$ glass spheres (pebbles). The pebbles were poured gently (loosely) into the bed column without pressure or vibration. Three CT scans were performed at three axial levels $(0.0762 \mathrm{~m}, 0.1524 \mathrm{~m}$, and $0.2286 \mathrm{~m}$ from the bottom of the column). At end of this experiment, the pebbles were discharge from the bed and put in an external vessel then the pebbles were reloaded again into the column in the same packing way (gently pouring the pebbles into the container without any pressure or vibration) to check for reproducibility of the repacking. Three CT scans were performed at the same axial levels used during the first packing mode. A comparison between the radial variations in the void distribution of the two packing at the three different levels is given in Figure 12. Due to the stochastic nature of randomly packing the bed, it is impossible to obtain exact or identical packing. Hence, the repeated packing (packing 1 and packing 2) gives reasonable reproducibility 
as shown in Figure 12 except few radial locations where the difference between them is relatively large. The figure also shows that the variation in radial void distribution for both packing is still in a good agreement near the wall region. The average value of discrepancy for the both trends at the bulk region (Figure 12-b) was 1\% at the wall region and 38\% near the center.
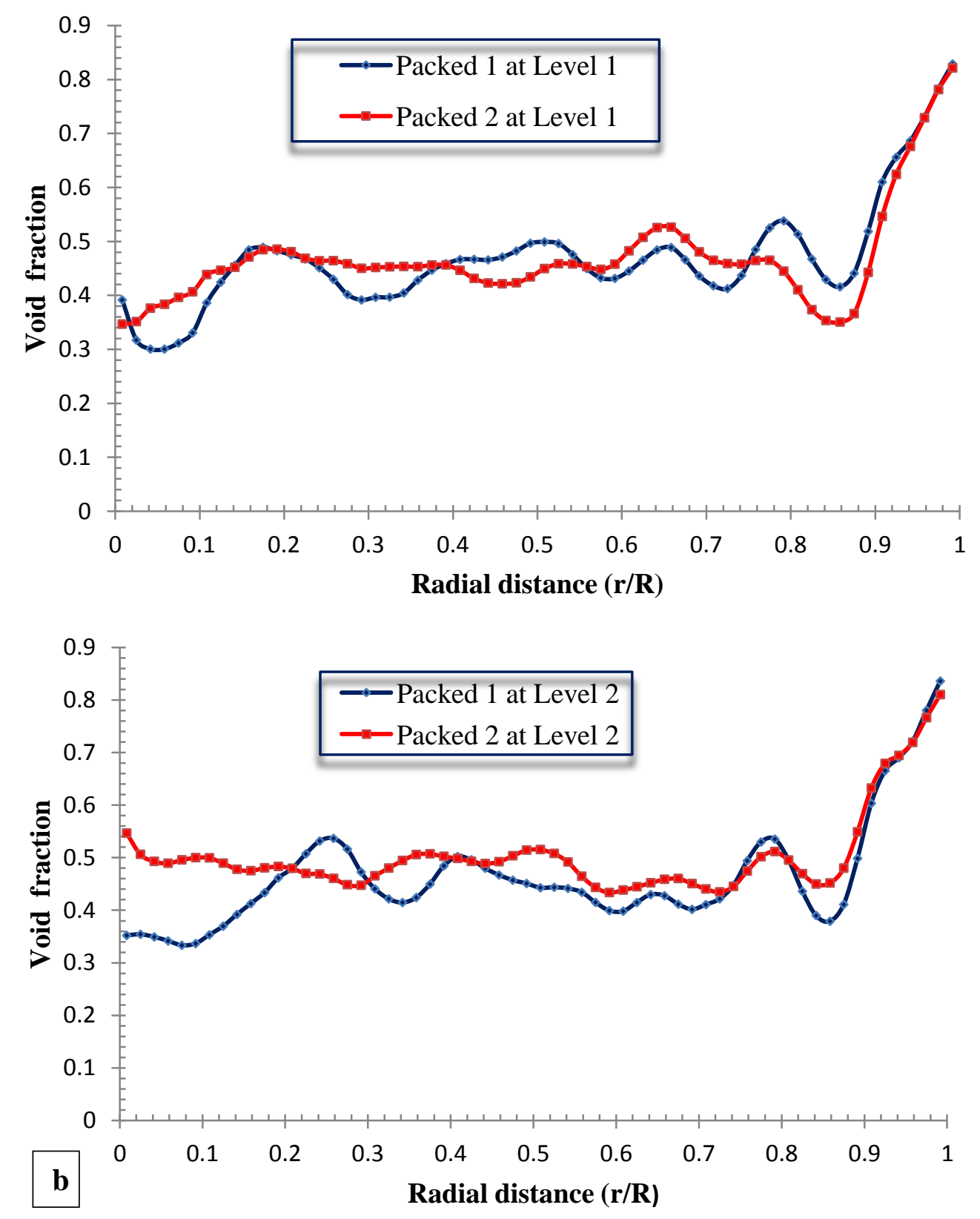


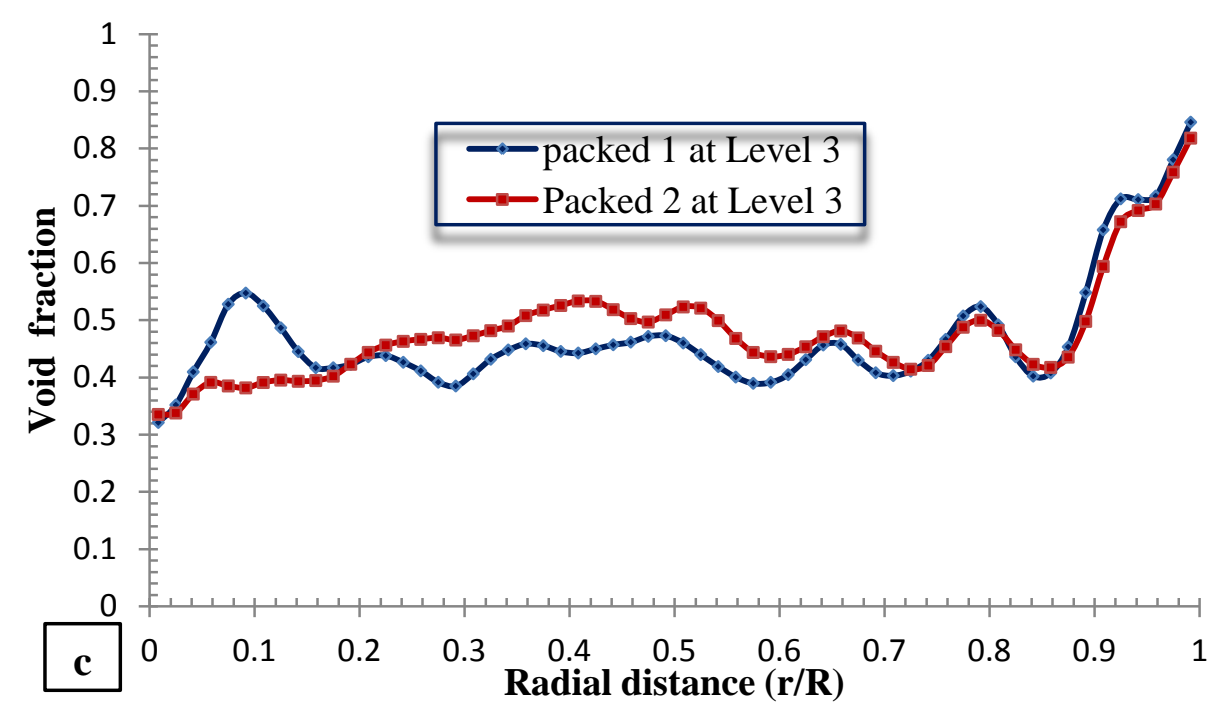

Figure 12: Azimuthally averaged radial void fraction profiles for the two packing reproducibility of $0.0254 \mathrm{~m}$ pebble diameter at different levels (a: Level $1=0.0762 \mathrm{~m}$, b: Level $2=$ $0.1524 \mathrm{~m}$ and $\mathrm{c}$ : Level $3=0.2286 \mathrm{~m}$ )

\section{c) Effect of adding additional load of pebbles on the top of the original bed on the void distribution}

An additional 1 foot tall bed of pebbles (232 pebbles) was added on the top of the original bed (226 pebbles). This new bed was filled with a total of 458 pebbles $(0.05 \mathrm{~m}$ in diameter). Irregular pebbles were removed to keep upper surface as flat and uniform as possible. Measurements of the azimuthally averaged of the void radial profiles were performed at the same three levels of $0.0762 \mathrm{~m}, 0.1524 \mathrm{~m}$, and $0.2286 \mathrm{~m}$ from the base for the new bed. The original bed was $0.3048 \mathrm{~m}$ height packed with 226 pebbles and the new bed was $0.6096 \mathrm{~m}$ height packed with 458 pebbles. These profiles were plotted in Figure 13. Void fraction profiles had the same oscillatory behavior in the void's variation in the radial direction, at all three levels. Adding an additional load of pebbles as an additional packing section did not affect the radial void distribution of the pebble bed measured at the levels of the original bed before adding the new load of pebbles. These results are in agreement with Toit's finding [8] stated that a pebble bed reactor's packing seems to be a slightly looser packing, and the sphere's weight does not seem to have a significant impact on the void bulk value's uniformity. 

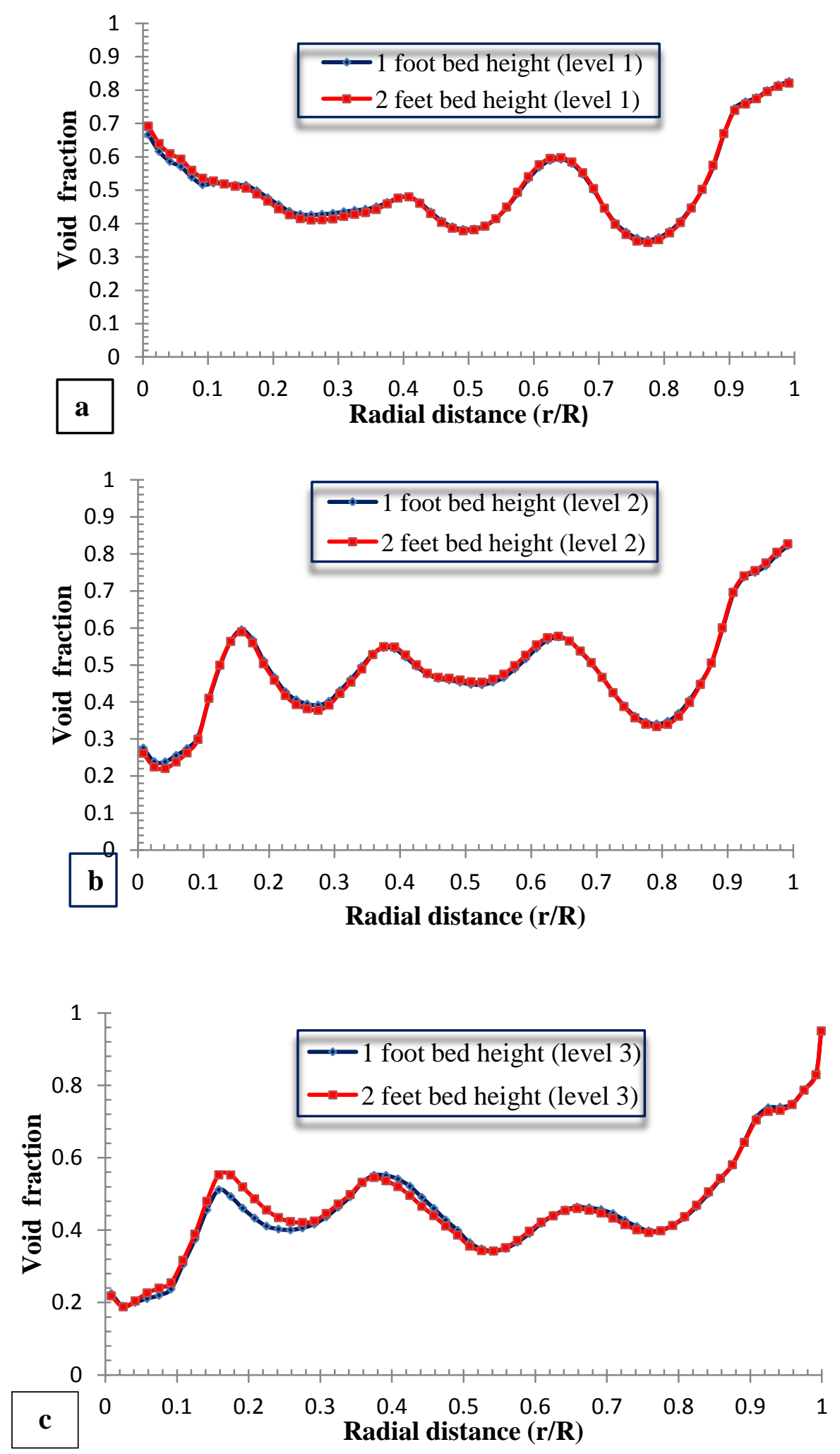

Figure 13: Radial variation in the void fractions of two bed heights at three different axial levels: a) $0.0762 \mathrm{~m}, \mathrm{~b}) 0.1524 \mathrm{~m}$, and c) $0.2286 \mathrm{~m}$ ) 


\subsection{AXIAL VOID FRACTION PROFILE AND 3D VISUALIZATION OF A PEBBLE BED REACTOR'S INNER STRUCTURE}

\section{a) Axial Variation of the bed structure}

A spatial cross-sectional void fraction distribution of a pebble bed packed with $0.025 \mathrm{~m}$ pebbles is given in Figure 14 at three axial levels $(0.0762 \mathrm{~m}, 0.1524 \mathrm{~m}$, and $0.2286 \mathrm{~m}$ above the bed base). The details that are illustrated in these images are important to understanding the structure of a packed sphere: different planes have different void distributions as shown in the histogram of void distribution for each level. These distributions are dependent on the internal friction between the spheres and between the spheres and the column wall. The planes (crosssections) are separated by nearly $0.0762 \mathrm{~m}$ ( 3 sphere diameter).
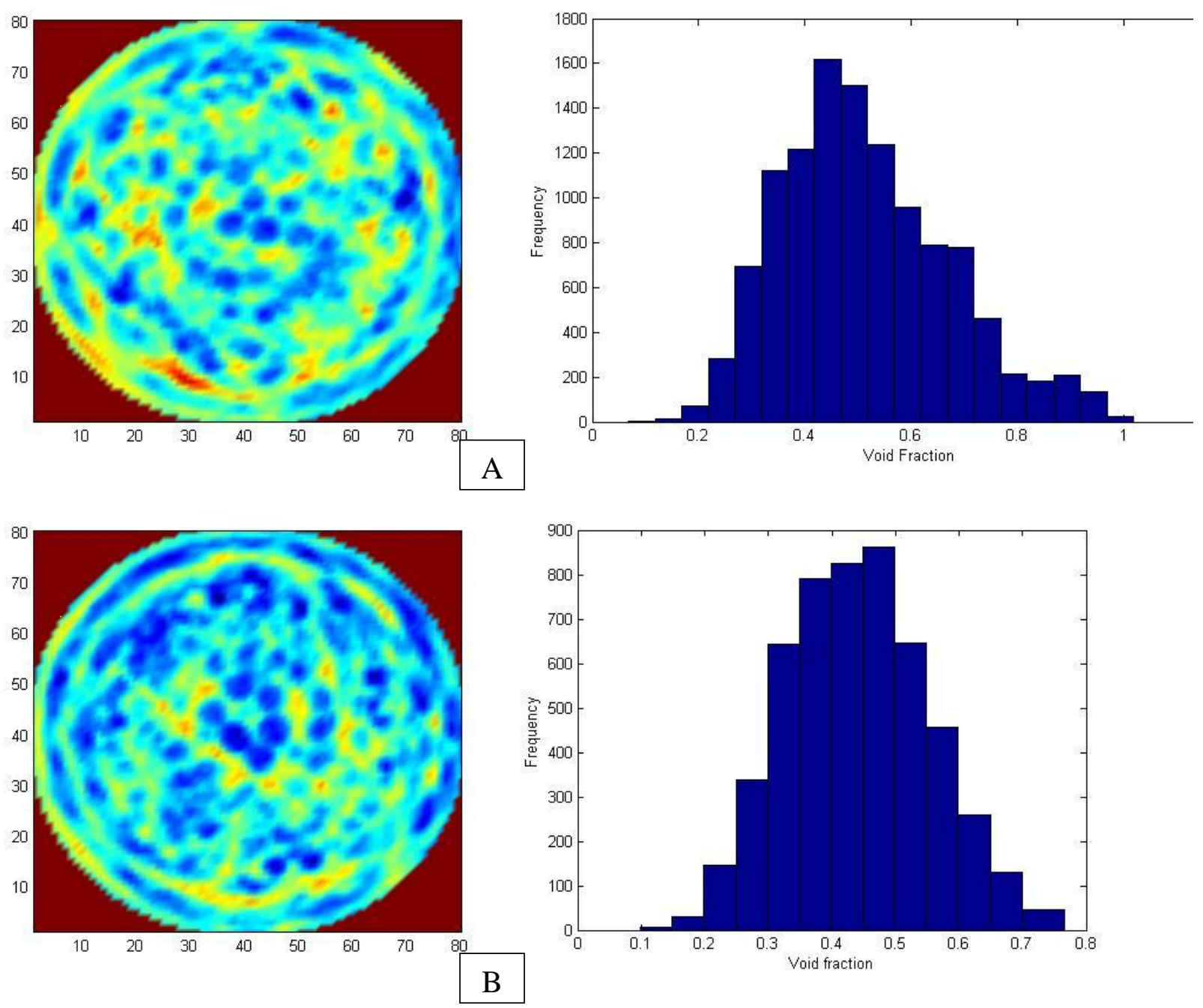

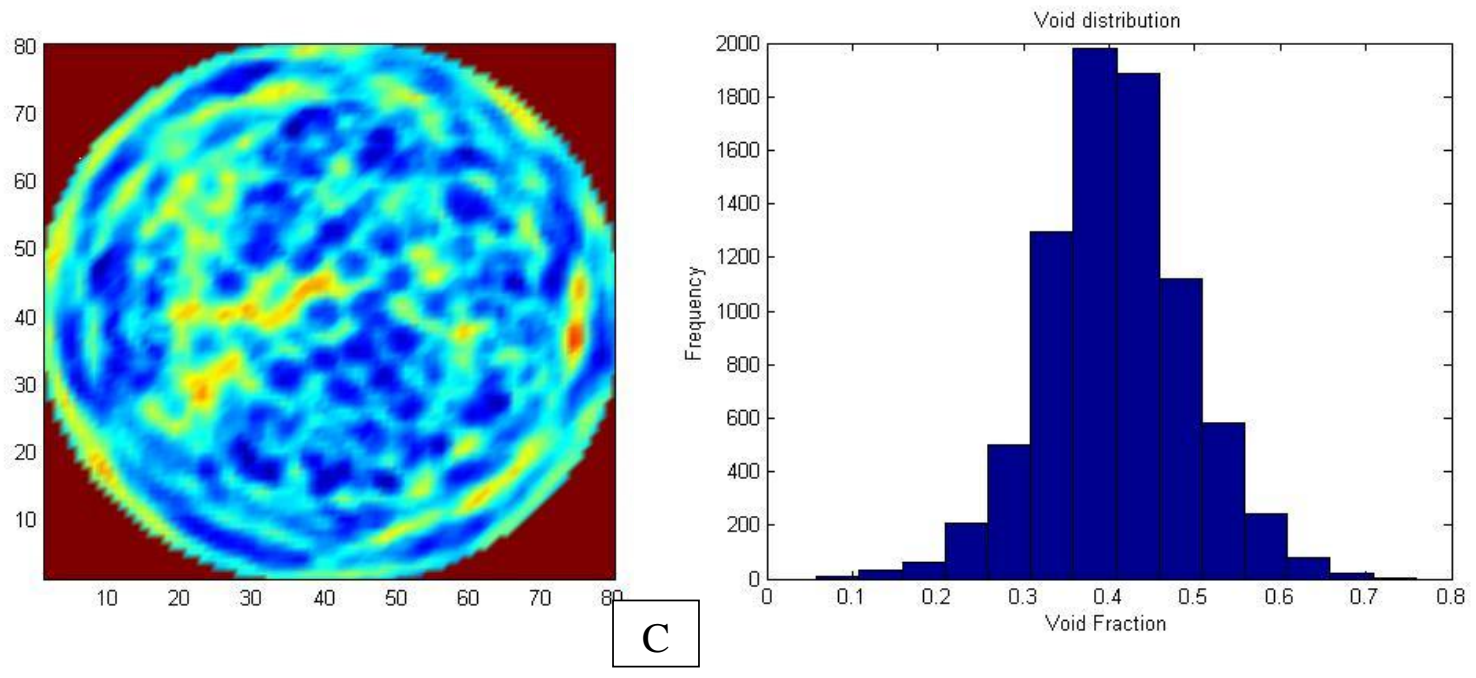

Figure 14: Spatial cross-sectional void fraction distribution and histograms in a $0.3 \mathrm{~m}$ packed bed column packed with $(0.025 \mathrm{~m})$ marbles at a height of (A) $0.0762 \mathrm{~m}$, (B) $0.1524 \mathrm{~m}$, and $(\mathrm{C}) 0.2286 \mathrm{~m}$, from the base of the bed

\section{b) Axial Void Fraction Distribution in a Pebble Bed Reactor.}

Axial void fraction profiles were measured using a bed of $0.3 \mathrm{~m}$ diameter and $0.3 \mathrm{~m}$ height packed with $0.0254 \mathrm{~m}$ diameter pebbles. About 1750 glass pebbles were used. The axial void fraction profile was determined by cross-sectionally averaged the void of the CT scan crosssection at that level. 20 cross-sectional slices were scanned by the gamma tomography (CT) along the bed height. Each averaged void cross-section will give one data point of axial void. Thus, 20 data points of the void fraction were obtained in the vertical direction of the pebble bed (see Figure 15). The fluctuation of the void fraction in the bed's bottom was more pronounced than that at the top because of the bottom wall's influence on the packing structure (the spheres were more structurally packed in the bottom). No boundary effects in the axial profile's top region. This finding was expected because the upper side was a free boundary, which impressed no restraints on the pebble locations.

\section{c) 3D Visualization of the Pebble Bed Structure.}

The data obtained from several cross-sectional slices along the bed's height were used to develop a spatial 3D visualization computer code. Twenty cross-section slices were used to reconstruct 3D images in a cylindrical column that was 1 foot tall and had a 1 foot inner diameter. 


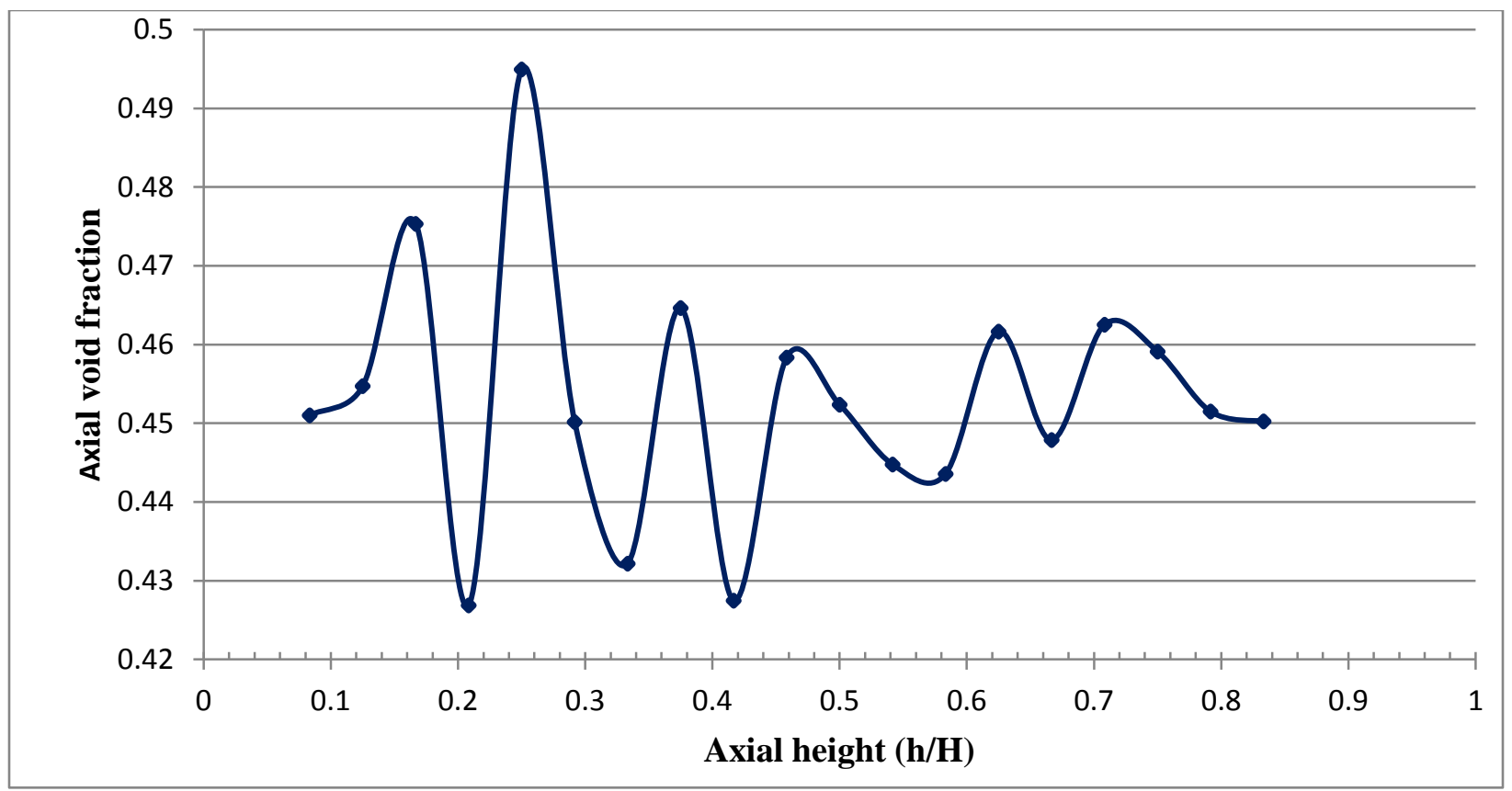

Figure 15: Axial void fraction distribution for $(\mathrm{D} / \mathrm{d}=12)$ pebble bed reactor

This cylinder was packed randomly with 17501 inch glass spheres. Despite the difficulties to visualize complex volume such as the pebble bed structure, attempt was made to reconstruct the 20 sectional slices, using gamma ray tomography $(\mathrm{CT})$, to obtain a spatial 3D image of the entire bed, shown in Figure 16. With higher resolution data one can get even better illustration of the packing structure through the $3 \mathrm{D}$ visualization. The $2 \mathrm{D}$ reconstructed void data was concatenated along a specified 3D model. The data was then smoothed. A convolution operation was used to filter the image linearly. Convolution is a neighborhood operation in which each output pixel is the weighted sum of the neighboring input pixels. The matrix of weights is referred to as the convolution kernel (also known as the filter). The isosurface data was computed last to create a $3 \mathrm{D}$ image. An isosurface is the $3 \mathrm{D}$ analog in an isoline; it is a surface that represents points of a constant value (e.g., void fraction) within a volume of space. Thus, an isosurface is a level set of a continuous function with a 3D-space domain. Isocaps were used to provide a visual context for the isosurfaces. They offer a cross-sectional view of the isosurface's interior for which the isocap provides an end cap. 


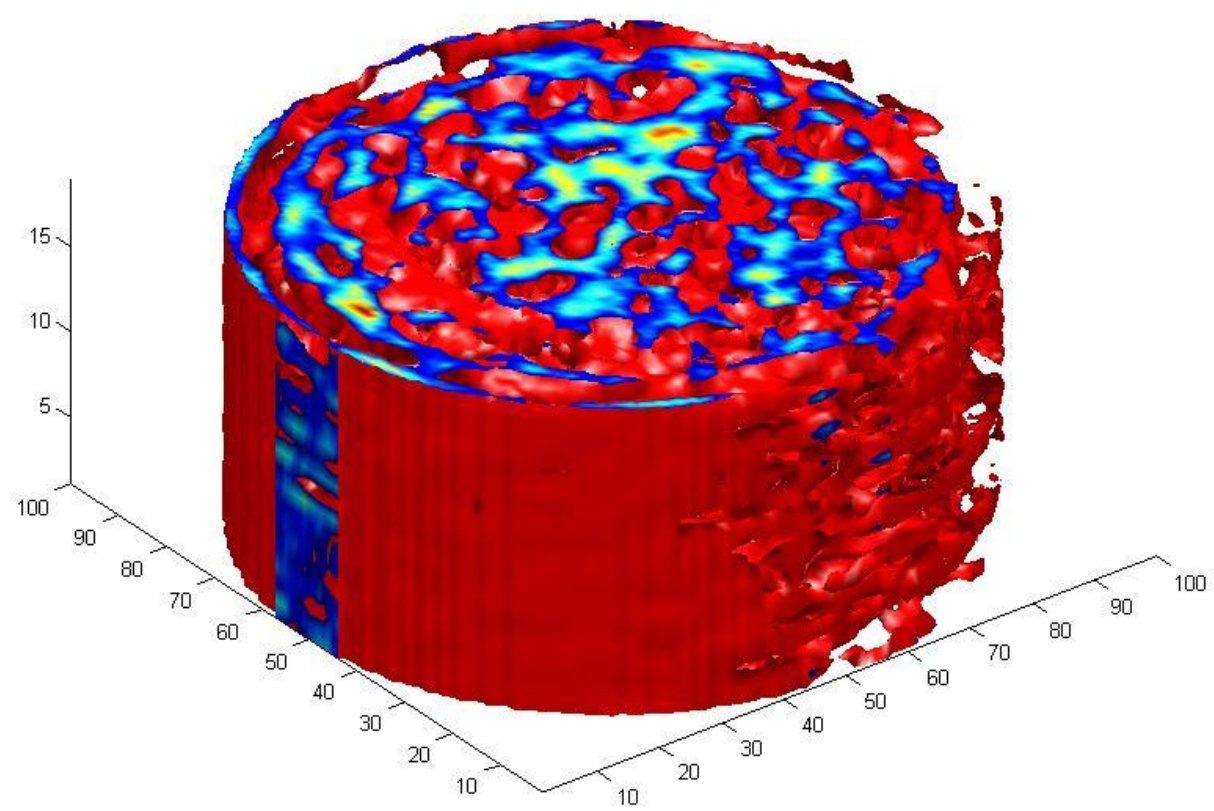

(a)
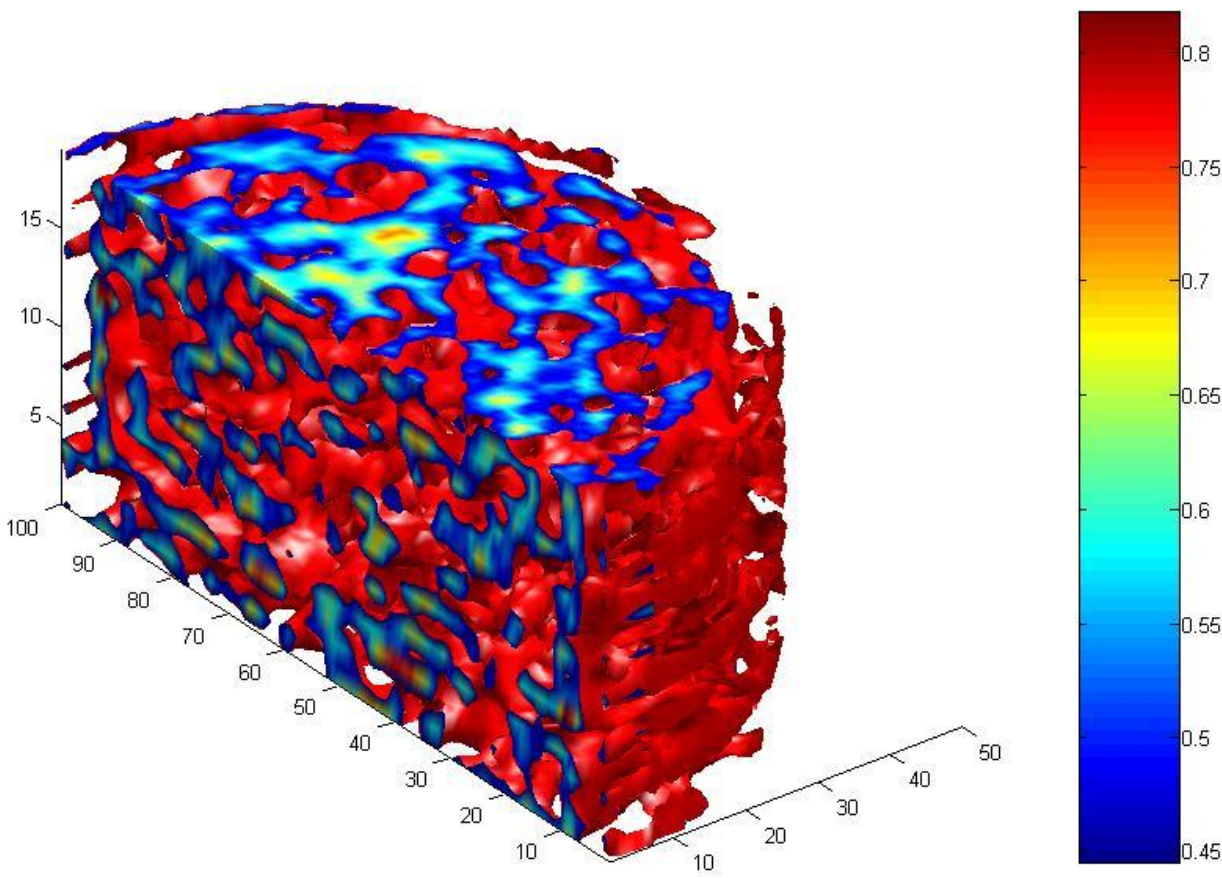

(b)

Figure 16: A spatial 3D visualization of the packing structure inside the cylindrical pebble bed using 20 cross-sectional distributions of CT scans (a) 3D view of the analyzed bed (b) Vertical cut section in the center of the bed 


\section{CONCLUDING REMARKS}

The structure of the pebble beds has been studied for the first time in terms of the time averaged voids cross-sectional distributions and their radial profiles using high energy-high resolution gamma ray computed tomography (CT). These experiments were successfully conducted in a $0.3 \mathrm{~m}$ diameter packed column using three different pebble sizes of glass spheres (Marbles) of $0.0127,0.0254$, and $0.05 \mathrm{~m}$ diameter. Horizontal scans taken at different vertical levels within the packed bed were made for each particle size. The obtained results indicate that the spatial porosity distribution in randomly packed columns is not uniform. Several pockets are always present in the packed beds, where the void is higher than the average value. The void distribution in randomly packed beds is dependent on the pebbles diameter and their characteristics, the bed diameter, etc. Increasing bed load of pebbles did not appear to influence the average voids and their radial profiles measured at the levels of the original bed. For the circumferentially averaged radial void distribution, the void near the center tends to be lower than that in the wall region due to the wall effect and the contacts between pebbles and between pebbles and the wall. The radial void fraction's profile exhibited large, dampened oscillations near the wall. The experimental results indicate that the porosity variation can be described by a normal distribution function in the packed bed's bulk region (middle height of the bed).

The results and findings of this work are useful to evaluate and validate the computational fluid dynamics codes such as discrete elements method, used to pack the bed, and the literature proposed correlations that have been suggested to simulate the void and the solids structure of the pebble bed. Furthermore, it is worth to mention here that in order to implement the thermal hydraulic computation on the cooling gas phase dynamics in pebble bed reactors, it is essential to provide the bed void structure as input to the used computational codes. This has been addressed in this work.

Acknowledgment: The US Department of Energy (DOE) Nuclear Energy Research Initiative (NERI) project (NERI-08-043) is acknowledged for providing the funding to pursue the research of this work. 


\section{References}

1. Boer B., 2008."Optimized core design and fuel management of a pebble-bed type Nuclear Reactor". IOS Press. ISBN 978-1-58603-966-0.

2. International Atomic Energy Agency. Nuclear power reactions in the world. Technical report IAEA-RDS-2/28, Vienna, Austria, July 2008. ISBN 978-92-0-107708-0.

3. GEN IV International Forum, 2007 Annual Report. Site web: www.gen-4.org. Last accessed, November 2014.

4. Letcher T. M., 2008. Future energy improved sustainable and clean options for our planet. Part III "Potentially important new types of energy", Elsevier.

5. Forsberg C. W. and Moses D. L., 2009. Safeguards challenges for pebble-bed reactors designed by People's Republic of china. Global nuclear security technology division. ORNL/TM-2008/229.

6. Chris H., Gary S., James W., and Martin Z. (20006): Analysis of granular flow in a pebblebed nuclear reactor

7. Banzant M. (2006): Modeling and simulation of granular flow in pebble bed nuclear reactor. Report to the department of energy, office of advanced scientific computer research.

8. Toit G. G., (2008): Radial variation in porosity in annular packed beds. Nuc. Eng. \& Design, 238, 3037-3079.

9. Cogliati J. and Ougouag A. (2006): Pebbles: A computer code for modeling packing, flow and re-circulation of pebbles in a pebble bed reactor. $3^{\text {rd }}$ International tropical meeting on high temperature reactor technology, Proceedings HTR2006, Johannesburg, South Africa.

10. Zhang w., Thompson K., Reed A., and Beenken L. (2006): Relationship between packing structure and porosity in fixed beds of equilateral cylindrical particles. Che. Eng Sci., 61, 8060-8074.

11. Roblee L. H., Baird R. M. and Tierney J. W. (1958): Radial porosity variations in packed beds. AIChE Journal, 4, pp. 460-464.

12. Benenati R. F. and Brosilow C. B. (1962): Void fraction distribution in beds of spheres. AIChE Journal, 8, pp. 359-361. 
13. Goodling J., Vachon R., Stelpflug W. and Ying S. (1983): Radial porosity distribution in cylindrical beds packed with spheres. Powder Technology, 35, pp. 23-29.

14. Kufner R. and Hofman H. (1990): Implementation of radial porosity and velocity distribution in a reactor model for heterogeneous catalytic gas phase reactors. Chem. Eng. Sci, Vol. 45, No. 8, pp. 2141-2146.

15. Mueller G. (1992): Radial void fraction distributions in randomly packed fixed beds of uniformly sized Spheres in cylindrical containers. Powder Technology, 72, pp. 269-275.

16. Niu M., Akiyama T., Takahashi R. and Yagi J. (1996): Reduction of the wall effect in a packed bed by hemispherical lining. AIChE Journal, 42, pp. 1181-1186.

17. Sederman A., Alexander P. and Gladden L. (2001): Structure of packed beds probed by magnetic resonance imaging. Powder Technology, 117, pp. 255-269.

18. Hassan A. Y. and Dominguez-Ontiveros E. E. (2008): Flow visualization in a pebble bed reactor experiment using PIV and refractive index matching techniques. Nuc. Eng. \& Design, 238, 3080-3085.

19. Mariani N., Salvat W., Campesi A., Barreto G. and Martinez (2009): Evaluation of structural properties of cylindrical packed beds using numerical simulations and tomography experiments. International Journal of Chemical Reactor Engineering, Vol. 7, Article A82.

20. Auwerda G., Kloosterman J., Winkelman A., Groen J., Dijk V. (2010): Comparison of experiments and calculations of void fraction distributions in randomly stacked pebble beds. Advan. Phys. To power the Nuc. Renaissance, Pittsburg, Pennsylvania, U.S.A.

21. Lee N. Y., Jung S. H., and Kim J. B. (2009): Evaluation of the measurement geometries and data processing algorithms for industrial gamma tomography technology. Applied radiation and isotopes, 67, 1441-1444.

22. Aboulwafa M. and Kendall E. (1980): The measurement of component ratios in multiphase systems using gamma ray attenuation, J. Phys. E: Sci Instrum., 13, 341-345.

23. Harrison M. (1990): Gamma scan evaluation for distillation column debottlenecking, Chem. Eng. Progress, 86, 37-44. 
24. Bowman J. (1993): Use column scanning for predictive maintenance. Chem. Eng. Progress, $89,34-41$.

25. Kumar S. (1994). Computed tomographic measurements of void fraction and modeling of the flow in bubble columns [PhD Thesis]: Florida Atlantic University

26. Kumar S., Moslemian D., and Dudukovic M. (1997): Gas-holdup measurements in bubble columns using computed tomography. AIChE Journal, 43(6):1414-1425.

27. Chaouki, J., Larachi, F., Dudukovic, M. P. (1997): Noninvasive tomographic and velocimetric monitoring of multiphase flows. Industrial \& Engineering Chemistry Research, 36 (11), 4476-4503.

28. Roy S. (2000): Quantification of two phase flow in liquid-solid risers. D.Sc. Thesis, Washington University, St Louis, MO.

29. Chen, J., N. Rados, M. H. Al-Dahhan, M. P. Dudukovic, D. Nguyen and K. Parimi (2001): Particle motion in packed/ ebullated beds by CT and CARPT. AIChE Journal, 47(5): 9941004.

30. Wang Z., Afacan A., Nandakumar K., Chuang K., (2001): Porosity distribution in random packed columns by gamma ray tomography. Chem. Eng. And Process, 40, 209-219.

31. Rados N. (2003): Slurry bubble column hydrodynamics. D.Sc. Thesis, Washington University, St. Louis, MO.

32. Roy S., Kemoun A., Al-Dahhan M., Dudukovic M., Skourlis T., Dautzenberg F. (2004): Countercurrent flow distribution in structured packing via computed tomography. Chemical Engineering and Processing 44(1):59-69.

33. Rados N., Shaikh A., Al-Dahhan M. (2005): Phase distribution in a high pressure slurry bubble column via a single source computed tomography. The Canadian Journal of Chemical Engineering, 83:104-112.

34. Hampel U., Bieberle A., Hoppe D., Kronenberg J., Schlecher E., Suhnel T., Zimmermann F., Zippe C. (2007): High resolution gamma ray tomography scanner for flow measurements and non-destructive testing applications. Review of Scientific Instruments 78, 103704.

35. Varma R., (2008): Characterization of anaerobic bioreactors for bio-energy generation using a novel tomography technique. D.Sc. thesis, Washington University, St. Louis, MO. 
36. Vasquez P., Mesquita C., LeRoux G., Hamada M. (2010): Methodological analysis of gamma tomography system for large random packed columns. Appl. Rad. and Isotopes, 68, 658-661.

37. Almesfer M., Ahmed F., Neogi P., and Al-Dahhan M. (2012): Effect of internals on gas holdup in bubble columns using computed Tomography (CT). 6th International symposium on process tomography.

38. Ahmed F., Almesfer M., and Al-Dahhan M. (2012): Bed structure characterization of pebble bed reactor using Gamma-Ray Tomography. 6th International symposium on process tomography.

39. Dijk V. (2008): Radial void fraction measurement of randomly packed pebble bed. Thesis, Delft University of Technology, Delft, Netherlands.

40. Vesvikar MS. (2006): Understanding the hydrodynamics of anaerobic digesters for bioenergy production [D.Sc.]: Washington University-St. Louis.

41. Varma R, 2008: Characterization of anaerobic bioreactors for bioenergy generation using a novel tomography technique [D.Sc.]: Washington University-St. Louis.

42. Saint-Gobain (2004): Efficiency calculations for selected scintillators Saint-Gobain Crystals. Web, (http://www.detectors.saint-gobain.com/) p. 16.

43. O'Sullivan J. A., and Benac J., (2007): Alternating Minimization algorithms for transmission tomography. Medical Imaging, IEEE Transactions on 26, 3, 283-297.

44. Mueller G. E., (2010): Radial porosity in packed beds of spheres. Powder Technol., 203, 626-633.

45. Romeu A. P., Jorg R. and Claudio F. (2011): Tomography analysis of the inner structure of pebbles and pebble beds. Adv. Eng. Mat. 13, No.3, 145-155. 


\section{References}

1. Boer B., 2008."Optimized core design and fuel management of a pebble-bed type Nuclear Reactor". IOS Press. ISBN 978-1-58603-966-0.

2. International Atomic Energy Agency. Nuclear power reactions in the world. Technical report IAEA-RDS-2/28, Vienna, Austria, July 2008. ISBN 978-92-0-107708-0.

3. GEN IV International Forum, 2007 Annual Report. Site web: www.gen-4.org. Last accessed, November 2014.

4. Letcher T. M., 2008. Future energy improved sustainable and clean options for our planet. Part III "Potentially important new types of energy", Elsevier.

5. Forsberg C. W. and Moses D. L., 2009. Safeguards challenges for pebble-bed reactors designed by People's Republic of china. Global nuclear security technology division. ORNL/TM-2008/229.

6. Chris H., Gary S., James W., and Martin Z. (20006): Analysis of granular flow in a pebblebed nuclear reactor

7. Banzant M. (2006): Modeling and simulation of granular flow in pebble bed nuclear reactor. Report to the department of energy, office of advanced scientific computer research.

8. Toit G. G., (2008): Radial variation in porosity in annular packed beds. Nuc. Eng. \& Design, 238, 3037-3079.

9. Cogliati J. and Ougouag A. (2006): Pebbles: A computer code for modeling packing, flow and re-circulation of pebbles in a pebble bed reactor. $3^{\text {rd }}$ International tropical meeting on high temperature reactor technology, Proceedings HTR2006, Johannesburg, South Africa.

10. Zhang w., Thompson K., Reed A., and Beenken L. (2006): Relationship between packing structure and porosity in fixed beds of equilateral cylindrical particles. Che. Eng Sci., 61, 8060-8074.

11. Roblee L. H., Baird R. M. and Tierney J. W. (1958): Radial porosity variations in packed beds. AIChE Journal, 4, pp. 460-464.

12. Benenati R. F. and Brosilow C. B. (1962): Void fraction distribution in beds of spheres. AIChE Journal, 8, pp. 359-361. 
13. Goodling J., Vachon R., Stelpflug W. and Ying S. (1983): Radial porosity distribution in cylindrical beds packed with spheres. Powder Technology, 35, pp. 23-29.

14. Kufner R. and Hofman H. (1990): Implementation of radial porosity and velocity distribution in a reactor model for heterogeneous catalytic gas phase reactors. Chem. Eng. Sci, Vol. 45, No. 8, pp. 2141-2146.

15. Mueller G. (1992): Radial void fraction distributions in randomly packed fixed beds of uniformly sized Spheres in cylindrical containers. Powder Technology, 72, pp. 269-275.

16. Niu M., Akiyama T., Takahashi R. and Yagi J. (1996): Reduction of the wall effect in a packed bed by hemispherical lining. AIChE Journal, 42, pp. 1181-1186.

17. Sederman A., Alexander P. and Gladden L. (2001): Structure of packed beds probed by magnetic resonance imaging. Powder Technology, 117, pp. 255-269.

18. Hassan A. Y. and Dominguez-Ontiveros E. E. (2008): Flow visualization in a pebble bed reactor experiment using PIV and refractive index matching techniques. Nuc. Eng. \& Design, 238, 3080-3085.

19. Mariani N., Salvat W., Campesi A., Barreto G. and Martinez (2009): Evaluation of structural properties of cylindrical packed beds using numerical simulations and tomography experiments. International Journal of Chemical Reactor Engineering, Vol. 7, Article A82.

20. Auwerda G., Kloosterman J., Winkelman A., Groen J., Dijk V. (2010): Comparison of experiments and calculations of void fraction distributions in randomly stacked pebble beds. Advan. Phys. To power the Nuc. Renaissance, Pittsburg, Pennsylvania, U.S.A.

21. Lee N. Y., Jung S. H., and Kim J. B. (2009): Evaluation of the measurement geometries and data processing algorithms for industrial gamma tomography technology. Applied radiation and isotopes, 67, 1441-1444.

22. Aboulwafa M. and Kendall E. (1980): The measurement of component ratios in multiphase systems using gamma ray attenuation, J. Phys. E: Sci Instrum., 13, 341-345.

23. Harrison M. (1990): Gamma scan evaluation for distillation column debottlenecking, Chem. Eng. Progress, 86, 37-44. 
24. Bowman J. (1993): Use column scanning for predictive maintenance. Chem. Eng. Progress, $89,34-41$.

25. Kumar S. (1994). Computed tomographic measurements of void fraction and modeling of the flow in bubble columns [PhD Thesis]: Florida Atlantic University

26. Kumar S., Moslemian D., and Dudukovic M. (1997): Gas-holdup measurements in bubble columns using computed tomography. AIChE Journal, 43(6):1414-1425.

27. Chaouki, J., Larachi, F., Dudukovic, M. P. (1997): Noninvasive tomographic and velocimetric monitoring of multiphase flows. Industrial \& Engineering Chemistry Research, 36 (11), 4476-4503.

28. Roy S. (2000): Quantification of two phase flow in liquid-solid risers. D.Sc. Thesis, Washington University, St Louis, MO.

29. Chen, J., N. Rados, M. H. Al-Dahhan, M. P. Dudukovic, D. Nguyen and K. Parimi (2001): Particle motion in packed/ ebullated beds by CT and CARPT. AIChE Journal, 47(5): 9941004.

30. Wang Z., Afacan A., Nandakumar K., Chuang K., (2001): Porosity distribution in random packed columns by gamma ray tomography. Chem. Eng. And Process, 40, 209-219.

31. Rados N. (2003): Slurry bubble column hydrodynamics. D.Sc. Thesis, Washington University, St. Louis, MO.

32. Roy S., Kemoun A., Al-Dahhan M., Dudukovic M., Skourlis T., Dautzenberg F. (2004): Countercurrent flow distribution in structured packing via computed tomography. Chemical Engineering and Processing 44(1):59-69.

33. Rados N., Shaikh A., Al-Dahhan M. (2005): Phase distribution in a high pressure slurry bubble column via a single source computed tomography. The Canadian Journal of Chemical Engineering, 83:104-112.

34. Hampel U., Bieberle A., Hoppe D., Kronenberg J., Schlecher E., Suhnel T., Zimmermann F., Zippe C. (2007): High resolution gamma ray tomography scanner for flow measurements and non-destructive testing applications. Review of Scientific Instruments 78, 103704.

35. Varma R., (2008): Characterization of anaerobic bioreactors for bio-energy generation using a novel tomography technique. D.Sc. thesis, Washington University, St. Louis, MO. 
36. Vasquez P., Mesquita C., LeRoux G., Hamada M. (2010): Methodological analysis of gamma tomography system for large random packed columns. Appl. Rad. and Isotopes, 68, 658-661.

37. Almesfer M., Ahmed F., Neogi P., and Al-Dahhan M. (2012): Effect of internals on gas holdup in bubble columns using computed Tomography (CT). 6th International symposium on process tomography.

38. Ahmed F., Almesfer M., and Al-Dahhan M. (2012): Bed structure characterization of pebble bed reactor using Gamma-Ray Tomography. 6th International symposium on process tomography.

39. Dijk V. (2008): Radial void fraction measurement of randomly packed pebble bed. Thesis, Delft University of Technology, Delft, Netherlands.

40. Vesvikar MS. (2006): Understanding the hydrodynamics of anaerobic digesters for bioenergy production [D.Sc.]: Washington University-St. Louis.

41. Varma R, 2008: Characterization of anaerobic bioreactors for bioenergy generation using a novel tomography technique [D.Sc.]: Washington University-St. Louis.

42. Saint-Gobain (2004): Efficiency calculations for selected scintillators Saint-Gobain Crystals. Web, (http://www.detectors.saint-gobain.com/) p. 16.

43. O'Sullivan J. A., and Benac J., (2007): Alternating Minimization algorithms for transmission tomography. Medical Imaging, IEEE Transactions on 26, 3, 283-297.

44. Mueller G. E., (2010): Radial porosity in packed beds of spheres. Powder Technol., 203, 626-633.

45. Romeu A. P., Jorg R. and Claudio F. (2011): Tomography analysis of the inner structure of pebbles and pebble beds. Adv. Eng. Mat. 13, No.3, 145-155. 